\title{
Synthesis and biological evaluation of tricyclic matrinic derivatives as a class of novel anti-HCV agents
}

\author{
Sheng Tang ${ }^{\dagger}$, Zong-Gen Peng ${ }^{\dagger}$, Ying-Hong Li, Xin Zhang, Tian-Yun Fan, Jian-Dong Jiang, Yan-Xiang Wang ${ }^{*}$ \\ and Dan-Qing Song*
}

\begin{abstract}
Background: $12 \mathrm{~N}$-benzyl matrinic acid analogues had been identified to be a novel scaffold of anti-HCV agents with a specific mechanism, and the representative compound $\mathbf{1}$ demonstrated a moderate anti-HCV activity. The intensive structure-activity relationship of this kind of compounds is explored so as to obtain anti-HCV candidates with good druglike nature.

Results: Taking compound $\mathbf{1}$ as the lead, 32 compounds (of which 27 were novel) with diverse structures on the 11-side chain, including methyl matrinate, matrinol, matrinic butane, (Z)-methyl $\Delta^{\beta \gamma}$-matrinic crotonate derivatives were synthesized and evaluated for their anti-HCV activities. Among all the compounds, matrinol $\mathbf{7 a}$ demonstrated potential potency with a greatly improved SI value of 136. Pharmacokinetic studies of $\mathbf{7 a}$ showed the potential for oral administration that would allow further in vivo safety studies. The free hydroxyl arm in $\mathbf{7 a}$ made it possible to prepare pro-drugs for the potential in the treatment of HCV infection.

Conclusions: 27 novel $12 \mathrm{~N}$-substituted matrinol derivatives were prepared. The SAR study indicated that the introduction of electron-donating substitutions on the benzene ring was helpful for the anti-HCV activity, and the unsaturated 11-side chain might not be favorable for the activity. This study provided powerful information on further strategic optimization and development of this kind of compounds into a novel family of anti-HCV agents.
\end{abstract}

Keywords: Matrinol, Hepatitis C virus, Structure-activity relationship, Druglike

\section{Background}

Currently, at least $130-150$ million people worldwide have been infected with hepatitis $\mathrm{C}$ virus (HCV) [1]. Each year, 3-4 million people are newly infected and HCV-related liver complications kill estimated 700,000 people annually $[1,2]$. In recent years, new direct acting antivirals (DAAs) specifically targeting $\mathrm{HCV}$ proteins have made a great breakthrough to HCV treatment, and NS3/4A HCV protease inhibitors telaprevir, boceprevir and simeprevir, NS5A inhibitors asunaprevir and ledipasvir, NS5B polymerase inhibitors sofosbuvir and dasabuvir

\footnotetext{
*Correspondence: wangyanxiang@imb.pumc.edu.cn; songdanqingsdq@hotmail.com

†Sheng Tang and Zong-Gen Peng equally contributed to this work Institute of Medicinal Biotechnology, Chinese Academy of Medical Sciences and Peking Union Medical College, Beijing 100050, China
}

have been approved by FDA for the HCV treatment successively since 2011 [3]. To deal with the springing up of drug resistance challenges [4-6], multiple of DAA combinations have been developed [7-9]. Therefore, it is still imperative to develop new anti-HCV agents with novel structure skeleton or mechanism of action as a new component to DAA combination.

In our earlier studies, $12 \mathrm{~N}$-benzyl matrinic acid analogues had been successfully identified to be a novel class of anti-HCV agents from matrine, a natural product extracted from traditional Chinese herb. The representative compound, 12N-4-methoxylbenzyl matrinic acid (1, Fig. 1) was identified to be active against HCV with a novel mechanism targeting on host protein $\mathrm{Hsc70}$ and demonstrated a moderate anti-HCV activity with $\mathrm{SI}$ over $22[10,11]$. The special tricyclic flexible scaffold and 

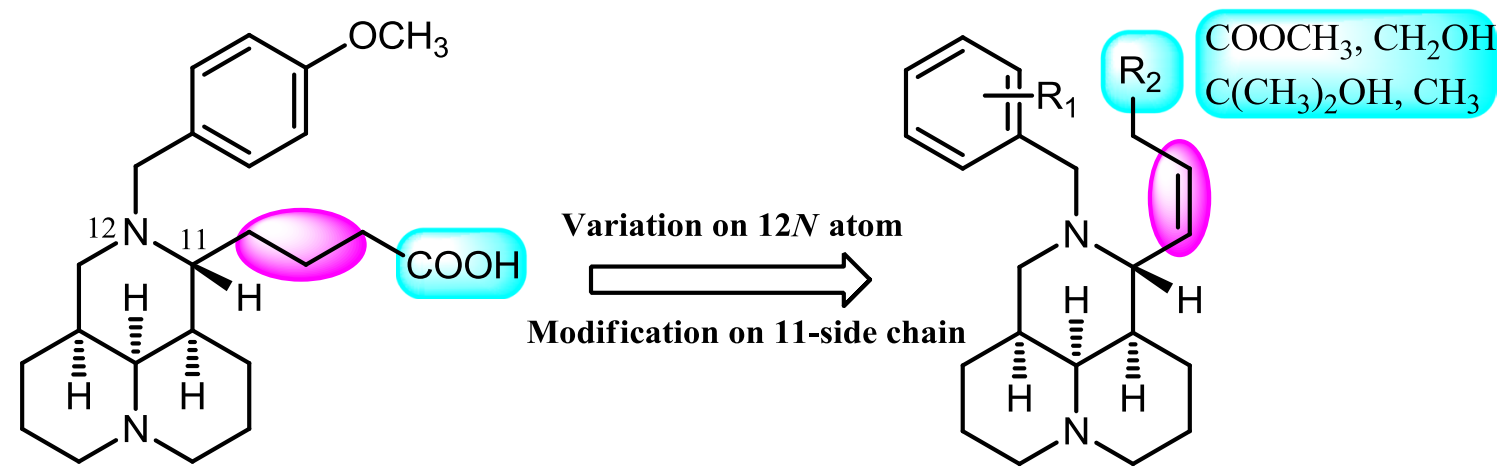

1, matrinic core

Fig. 1 Modification sites based on compound 1

appealing druglike of compound $\mathbf{1}$ strongly provoked our interesting to continuously explore the structure-activity relationship (SAR) of this kind of compounds, in an effort to discover novel anti-HCV candidates which could be used in the combination with current DAA.

In the present study, as illustrated in Fig. 1, taking 1 as the lead, SAR studies were further conducted with the variations of the 11-side chain and diverse substituents on $12 \mathrm{~N}$-atom. Therefore, series of novel methyl matrinate, matrinol, matrinic butane, $1^{\prime}, 1^{\prime}$-dialkyl matrinol, methyl $(Z)-\Delta^{\beta \gamma}$-matrinic crotonate and $(Z)-\Delta^{\beta \gamma}$-matrinic crotonl derivatives were designed, synthesized and evaluated for their in vitro anti-HCV activities as well as the in vivo pharmacokinetic (PK) and safety profile of the representative compounds.

\section{Results and discussion Chemistry}

As displayed in Schemes 1 and 2, all the target compounds were synthesized using commercially available matrine or lehmannine with purity over $98 \%$ as the starting material. As shown in Scheme 1, following the procedure of preparing compound 2 [12], the rest methyl matrinates $\mathbf{6 a}-\mathbf{f}$ were obtained from matrine through a three-step sequence including basic hydrolytic ringopening, methyl esterification, $12 \mathrm{~N}$-substitution via
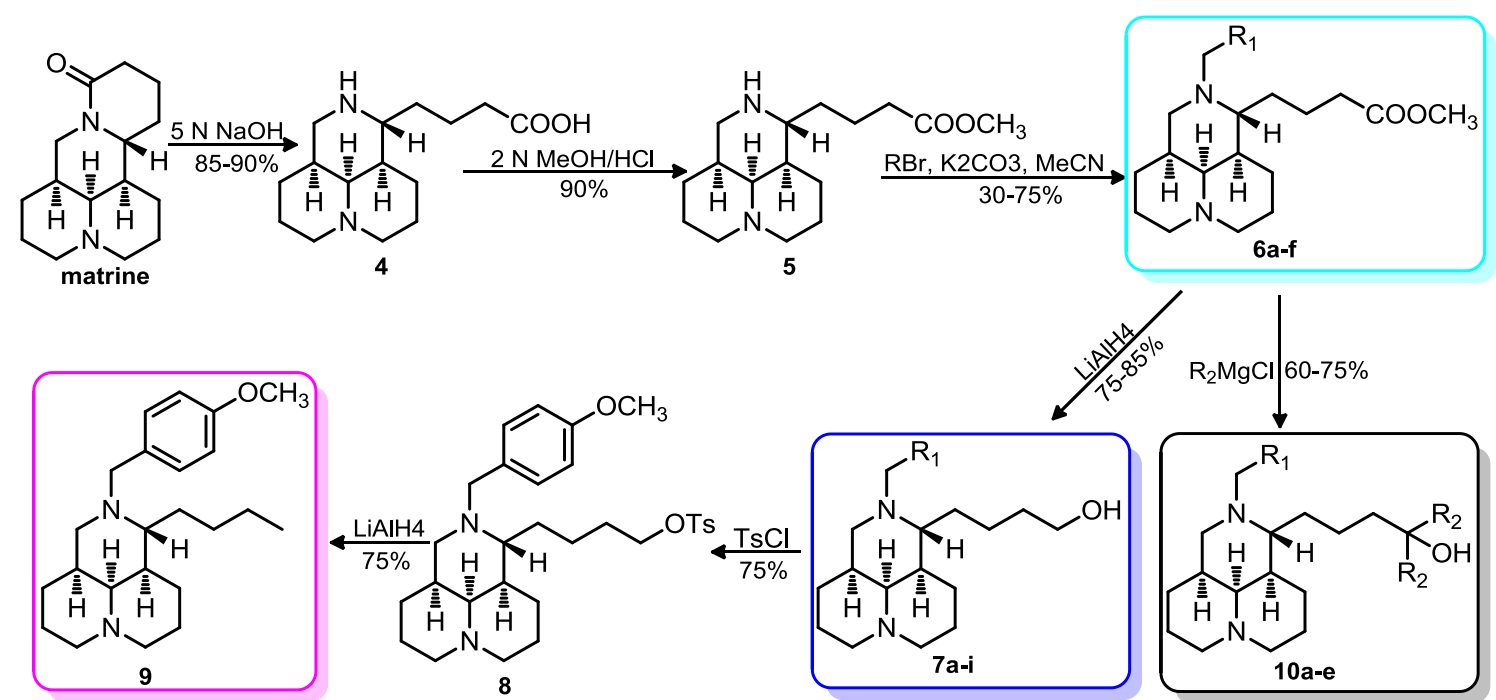

Scheme 1 Synthetic procedures of methyl matrinate and matrinol derivatives. Reagents and conditions: (a) $5 \mathrm{~N} \mathrm{NaOH}$, reflux, $9 \mathrm{~h}, 6 \mathrm{~N} \mathrm{HCl}$, $\mathrm{pH}=5-6 ;$ (b) $2 \mathrm{~N} \mathrm{MeOH} / \mathrm{HCl}$, reflux, $2 \mathrm{~h}$; (c) $\mathrm{RBr}_{2} \mathrm{~K}_{2} \mathrm{CO}_{3}, \mathrm{MeCN}$, r.t., overnight; (d) LiAlH ${ }_{4}$ THF, r.t., 30 min; (e) $\mathrm{R}_{2} \mathrm{MgCl}, \mathrm{THF}, 0-25^{\circ} \mathrm{C}$, reflux, 2 h; (f) TsCl, $\mathrm{CH}_{2} \mathrm{Cl}_{2}, \mathrm{TEA}$, 4-DMAP; (g) alkylmagnesium chloride, THF, reflux, $2 \mathrm{~h}$ 


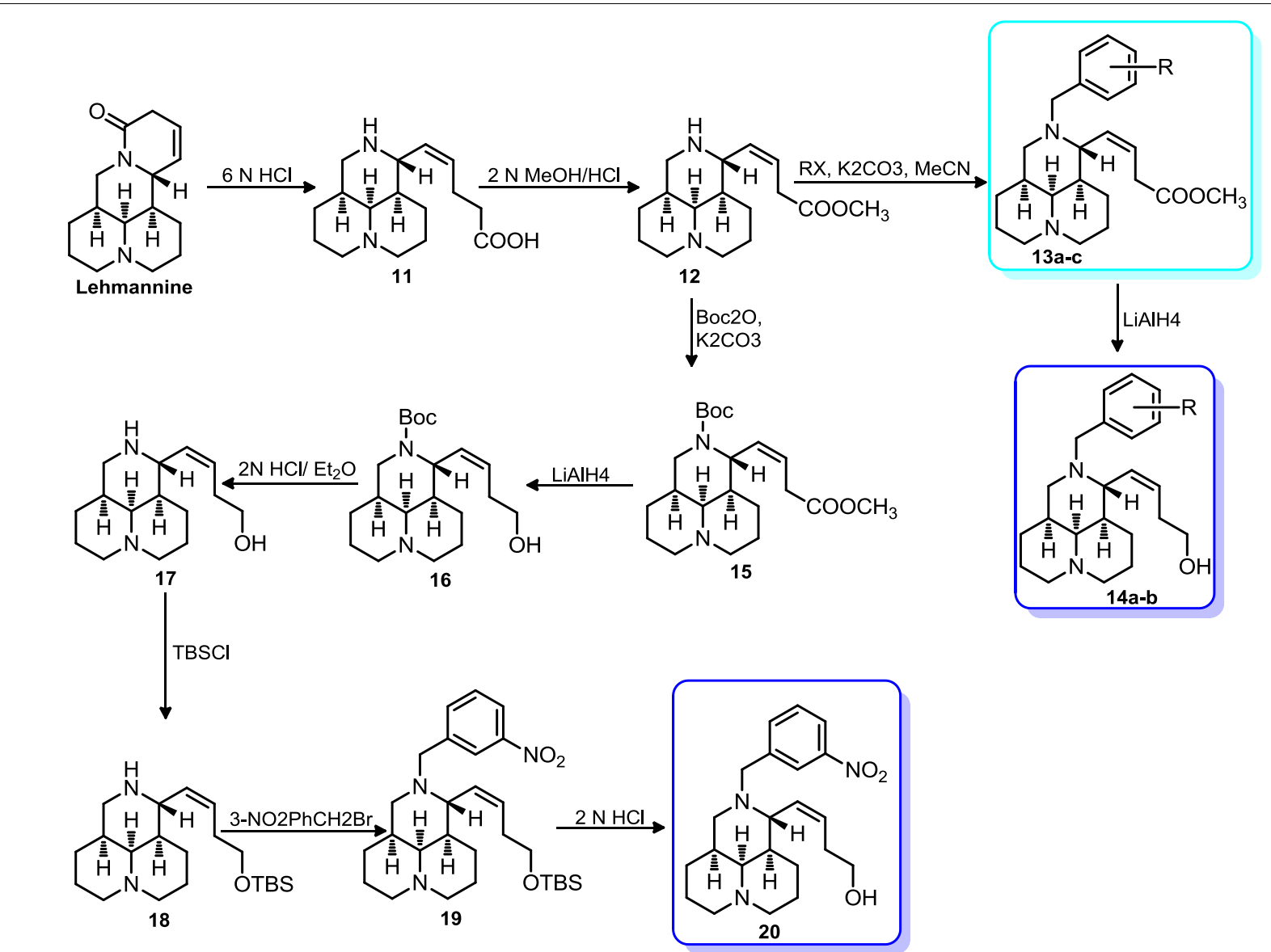

Scheme 2 Synthetic procedures of methyl (Z)- $\Delta^{\beta \gamma}$-matrinic crotonate and (Z)- $\Delta^{\beta \gamma}$-matrinic crotonol derivatives. Reagents and conditions: (a) $6 \mathrm{~N}$ $\mathrm{HCl}$, reflux, 9 h; (b) $2 \mathrm{~N} \mathrm{MeOH} / \mathrm{HCl}$, reflux, 2 h; (c) $\mathrm{RX}, \mathrm{K}_{2} \mathrm{CO}_{3}, \mathrm{MeCN}$, r.t., overnight; (d) LiAlH 4 , THF, r.t., 30 min; (e) $\mathrm{Boc}_{2} \mathrm{O}, \mathrm{K}_{2} \mathrm{CO}_{3}, \mathrm{CH}_{2} \mathrm{Cl}_{2}$, r.t., overnight; (f) $2 \mathrm{~N} \mathrm{HCl}_{\mathrm{EEt}} \mathrm{O}, 30 \mathrm{~min},(\mathbf{g}) \mathrm{TBSCl}, \mathrm{CH}_{2} \mathrm{Cl}_{2}$, imidazole, r.t., overnight; (h) 3- $\mathrm{NO}_{2} \mathrm{PhCH}_{2} \mathrm{Br}$, TEA, $\mathrm{CH}_{2} \mathrm{Cl}_{2}$, r.t., 4 h; (i) $2 \mathrm{~N} \mathrm{HCl}$

substituted benzyl halides or benzaldehydes with good yields of 44-68\% [13-17]. Similar to the preparation of 3a [12], the rest matrinols $7 \mathbf{a}-\mathbf{i}$ were obtained by the $\mathrm{LiAlH}_{4}$ reduction of the corresponding methyl matrinate 6 as described in Scheme 1 with yields of $75-85 \%$. The matrinic butane product 9 was achieved through hydroxyl sulfonylation, reductive-elimination of OTs by $\mathrm{LiAlH}_{4}$ from $7 \mathbf{a}$ in a yield of $56 \%$ and the alkylation of $\mathbf{6 a}-\mathbf{b}$ and $\mathbf{6 d}-\mathbf{f}$ with Grignard reagents afforded the $1^{\prime}, 1^{\prime}$-dialkyl substituted matrinols $\mathbf{1 0 a}-\mathbf{e}$ in yields of 60-75\% [12].

As depicted in Scheme 2, methyl $(Z)-\Delta^{\beta \gamma}$-matrinic crotonate derivatives $(\mathbf{1 3 a}-\mathbf{c})$ were obtained from lehmannine following the similar sequence including acidic hydrolytic ring-opening, methyl esterification, $12 \mathrm{~N}$-substitution with overall yields of 30-35\% [18]. The targeted $(Z)-\Delta^{\beta \gamma}$-matrinic crotonol derivatives $(\mathbf{1 4 a}-\mathbf{b})$ were gained from a $\mathrm{LiAlH}_{4}$ reduction of 13a-b in $70-80 \%$ yields. Another nitro substituted crotonol derivative $\mathbf{2 0}$ was obtained from compound $\mathbf{1 2}$ via a six-step procedure, including $12 \mathrm{~N}$-tert-butoxycarbonyl (Boc) protection, ester reduction by $\mathrm{LiAlH}_{4}$, de-protection of Boc, silicane protection, $12 \mathrm{~N}$-substitution and deprotection with an overall yield of $30 \%[14,15]$.

\section{Anti-HCV activity and SAR analysis of matrinol derivatives}

All the target compounds were evaluated for their anti$\mathrm{HCV}$ activities $\left(\mathrm{EC}_{50}\right)$ and cytotoxicities $\left(\mathrm{CC}_{50}\right)$ in human Huh7.5 cells using specific real-time RT-PCR assay, as described earlier [11]. As an important indicator, the selectivity index (SI) was calculated as a ratio of $\mathrm{CC}_{50}$ to $\mathrm{EC}_{50}$. Anti-HCV ability of a given compound was estimated by combining its $\mathrm{EC}_{50}$ with SI values. Totally 32 compounds were gathered, and their structures and antiHCV effects were shown in Table 1.

SAR investigation was initiated with the variation of carboxylic acid group, by which 7 methyl matrinates (2, $\mathbf{6 a}-\mathbf{f})$ and 13 matrinols (3a-d and $7 \mathbf{a}-\mathbf{i})$ were generated. As depicted in Table 1, except 4-nitrobenzyl derivative 6e, all methyl $12 N$-benzyl/pyridylmethyl substituted 
Table 1 SAR of all the targeted compounds for anti-HCV activity in Huh7.5 cells

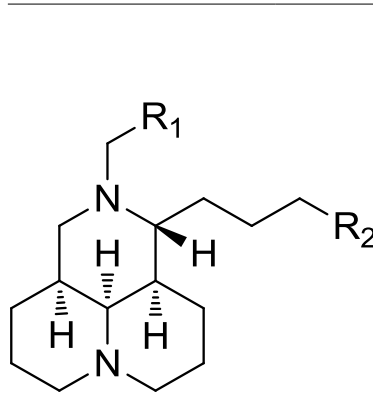

2, 3a-d, 6a-f and $7 \mathrm{a}-\mathrm{i}$

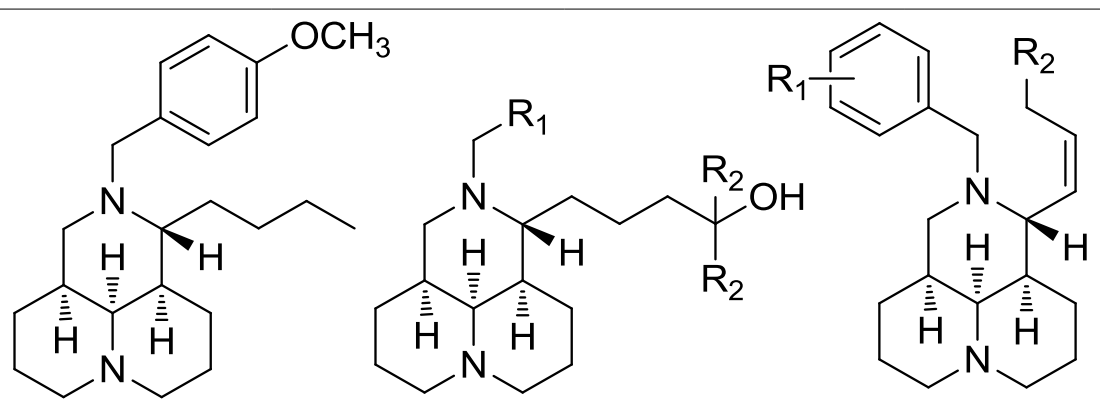

9 10a-e 13a-c, 14a-b and 20

\begin{tabular}{|c|c|c|c|c|c|}
\hline Code & $\mathbf{R}_{1}$ & $\mathbf{R}_{\mathbf{2}}$ & $\mathrm{CC}_{50}(\mu \mathrm{M})^{\mathrm{a}}$ & $E C_{50}(\mu M)^{b}$ & SI \\
\hline 1 & $\mathrm{C}_{6} \mathrm{H}_{4} \mathrm{OCH}_{3}-4$ & $\mathrm{COOH}$ & $>1000$ & $43.8 \pm 3.81$ & $>22.8$ \\
\hline 2 & $\mathrm{C}_{6} \mathrm{H}_{4} \mathrm{~F}-4$ & $\mathrm{COOCH}_{3}$ & $274 \pm 8.35$ & $2.09 \pm 1.65$ & 131 \\
\hline $3 a$ & $\mathrm{C}_{6} \mathrm{H}_{4} \mathrm{~F}-4$ & $\mathrm{CH}_{2} \mathrm{OH}$ & $285 \pm 7.45$ & $2.99 \pm 1.51$ & 95.3 \\
\hline $3 \mathbf{b}$ & $\mathrm{CH}_{2} \mathrm{CH}_{2} \mathrm{CH}_{3}$ & $\mathrm{CH}_{2} \mathrm{OH}$ & $>500$ & $16.4 \pm 10.9$ & $>30.5$ \\
\hline $3 c$ & $\mathrm{CH}_{2}\left(\mathrm{CH}_{2}\right)_{5} \mathrm{CH}_{3}$ & $\mathrm{CH}_{2} \mathrm{OH}$ & $33.3 \pm 6.49$ & $1.01 \pm 0.55$ & 32.9 \\
\hline $3 d$ & $\mathrm{CH}_{2}\left(\mathrm{CH}_{2}\right)_{6} \mathrm{CH}_{3}$ & $\mathrm{CH}_{2} \mathrm{OH}$ & $17.8 \pm 2.44$ & $0.80 \pm 0.26$ & 22.3 \\
\hline $6 a$ & $\mathrm{C}_{6} \mathrm{H}_{4} \mathrm{OCH}_{3}-4$ & $\mathrm{COOCH}_{3}$ & $414 \pm 7.34$ & $7.01 \pm 1.51$ & 59.1 \\
\hline $6 b$ & $\mathrm{C}_{6} \mathrm{H}_{4} \mathrm{CH}_{3}-4$ & $\mathrm{COOCH}_{3}$ & $132.9 \pm 7.53$ & $1.73 \pm 1.36$ & 76.8 \\
\hline $6 c$ & $\mathrm{C}_{6} \mathrm{H}_{4} \mathrm{CH}=\mathrm{CH}_{2}-4$ & $\mathrm{COOCH}_{3}$ & $81.2 \pm 12.9$ & $1.61 \pm 0.76$ & 50.4 \\
\hline $6 d$ & $\mathrm{C}_{6} \mathrm{H}_{3} \mathrm{~F}_{2}-2,4$ & $\mathrm{COOCH}_{3}$ & $261 \pm 28.7$ & $1.69 \pm 1.47$ & 154 \\
\hline $6 e$ & $\mathrm{C}_{6} \mathrm{H}_{4} \mathrm{NO}_{2}-4$ & $\mathrm{COOCH}_{3}$ & $235 \pm 48.2$ & $14.2 \pm 3.13$ & 16.5 \\
\hline $6 f$ & pyridyl-4 & $\mathrm{COOCH}_{3}$ & $>500$ & $4.66 \pm 0.35$ & $>107$ \\
\hline $7 a$ & $\mathrm{C}_{6} \mathrm{H}_{4} \mathrm{OCH}_{3}-4$ & $\mathrm{CH}_{2} \mathrm{OH}$ & $383 \pm 30.2$ & $2.81 \pm 0.82$ & 136 \\
\hline $7 \mathbf{b}$ & $\mathrm{C}_{6} \mathrm{H}_{4} \mathrm{CH}_{3}-4$ & $\mathrm{CH}_{2} \mathrm{OH}$ & $252 \pm 3.04$ & $<2.06$ & $>122$ \\
\hline $7 c$ & $\mathrm{C}_{6} \mathrm{H}_{4} \mathrm{CH}=\mathrm{CH}_{2}-4$ & $\mathrm{CH}_{2} \mathrm{OH}$ & $143 \pm 32.3$ & $3.16 \pm 0.51$ & 45.3 \\
\hline 7d & $\mathrm{C}_{6} \mathrm{H}_{3} \mathrm{~F}_{2}-2,4$ & $\mathrm{CH}_{2} \mathrm{OH}$ & $266 \pm 9.47$ & $<2.06$ & $>129$ \\
\hline $7 e$ & Pyrid-4-yl & $\mathrm{CH}_{2} \mathrm{OH}$ & $>500$ & $9.03 \pm 5.58$ & $>55.4$ \\
\hline $7 f$ & Pyrid-3-yl & $\mathrm{CH}_{2} \mathrm{OH}$ & $>500$ & $4.39 \pm 3.01$ & $>114$ \\
\hline $7 \mathbf{g}$ & pyrid-2-ylCl-5 & $\mathrm{CH}_{2} \mathrm{OH}$ & $>500$ & $10.9 \pm 5.59$ & $>45.9$ \\
\hline $7 \mathrm{~h}$ & $\mathrm{CONHC}_{6} \mathrm{H}_{4}$ & $\mathrm{CH}_{2} \mathrm{OH}$ & $>500$ & $46.7 \pm 41.0$ & $>10.7$ \\
\hline $7 \mathbf{i}$ & $\mathrm{CONHC}_{6} \mathrm{H}_{3} \mathrm{CF}_{3}-4$ & $\mathrm{CH}_{2} \mathrm{OH}$ & $86.2 \pm 4.33$ & $4.19 \pm 1.44$ & 20.6 \\
\hline 9 & & & $41.9 \pm 1.10$ & $1.16 \pm 0.25$ & 36.1 \\
\hline $10 a$ & $\mathrm{C}_{6} \mathrm{H}_{4} \mathrm{OCH}_{3}-4$ & $\mathrm{CH}_{3}$ & $>140 \pm 16.6$ & $11.7 \pm 0.06$ & 12.0 \\
\hline $10 b$ & $\mathrm{C}_{6} \mathrm{H}_{4} \mathrm{CH}_{3}-4$ & $\mathrm{CH}_{3}$ & $55.7 \pm 7.50$ & $0.82 \pm 0.26$ & 67.9 \\
\hline $10 c$ & $\mathrm{C}_{6} \mathrm{H}_{4} \mathrm{CH}_{3}-4$ & $\mathrm{C}_{2} \mathrm{H}_{5}$ & $12.3 \pm 4.23$ & $<0.23$ & $>53.5$ \\
\hline $10 d$ & $\mathrm{C}_{6} \mathrm{H}_{3} \mathrm{~F}_{2}-2,4$ & $\mathrm{CH}_{3}$ & $156 \pm 37.9$ & $6.55 \pm 2.69$ & 23.8 \\
\hline $10 \mathrm{e}$ & Pyrid-4-yl & $\mathrm{CH}_{3}$ & $>500$ & $80.4 \pm 24.3$ & 6.22 \\
\hline $13 a$ & $4-\mathrm{OCH}_{3}$ & $\mathrm{COOCH}_{3}$ & $326 \pm 21.0$ & $16.7 \pm 4.71$ & 19.5 \\
\hline $13 b$ & $4-\mathrm{F}$ & $\mathrm{COOCH}_{3}$ & $260 \pm 84.8$ & $18.1 \pm 6.49$ & 14.4 \\
\hline $13 c$ & $3-\mathrm{NO}_{2}$ & $\mathrm{COOCH}_{3}$ & $402 \pm 83.6$ & $40.4 \pm 3.64$ & 10.0 \\
\hline $14 a$ & $4-\mathrm{OCH}_{3}$ & $\mathrm{CH}_{2} \mathrm{OH}$ & $214 \pm 95.0$ & $8.80 \pm 2.15$ & 24.3 \\
\hline $14 b$ & $4-\mathrm{F}$ & $\mathrm{CH}_{2} \mathrm{OH}$ & $156 \pm 65.8$ & $13.6 \pm 2.63$ & 11.5 \\
\hline 20 & $3-\mathrm{NO}_{2}$ & $\mathrm{CH}_{2} \mathrm{OH}$ & $312 \pm 31.1$ & $18.4 \pm 1.64$ & 17.0 \\
\hline Tela & & & $47.6 \pm 0.61$ & $0.02 \pm 0.02$ & 1950 \\
\hline
\end{tabular}

Tela telaprevir

a Cytotoxic concentration required to inhibit Huh7.5 cell growth by $50 \%$

b Concentration required to inhibit HCV growth by $50 \%$ 
matrinates exerted higher activities than the lead 1 by showing lower $\mathrm{EC}_{50}$ values and higher SI values of over 50. In particular, $12 N$-4-fluorobenzyl 2, 4-methylbenzyl 6b, 4-vinylbenzyl $\mathbf{6 c}$ and 2,4-difluorobenzyl 6d displayed potent anti-HCV activities with $\mathrm{EC}_{50}$ values ranging from 1.61 to $2.09 \mu \mathrm{M}$, which were over 20 times more potent than that of $\mathbf{1}$. It appeared that the electron-donating substitutions on the benzene ring were more favorable than the electron-withdrawing groups in the methyl matrinate series.

Besides the substitutions mentioned above $(2, \mathbf{6 a}-\mathbf{d}$, 6f), 7 other substituents including long chain alkyl groups (3b-d), as well as pyridin-3-ylmethyl (7f), 5-chloropyridin-2-ylmethyl (7g), 2-oxo-2-(phenylamino)ethyl (7h), 2-oxo-2-((4- (trifluoromethyl) phenyl)amino)ethyl (7i) were also introduced on the $12 \mathrm{~N}$ atom to generate the library of matrinols. As anticipated, most of the $12 \mathrm{~N}$-benzyl/pyridyl substituted matrinols (3a and $7 \mathbf{a}-\mathbf{g}$ ) gave inspiring anti-HCV activities with $\mathrm{EC}_{50}$ values in the range of $2.06-10.9 \mu \mathrm{M}$, and SI values in the range of 45-136. In particular, compounds $7 \mathbf{a}, 7 \mathbf{b}$ and $\mathbf{7 d}$ bearing electron-donating methoxy, methyl and 2,4-difluoro substitutions respectively gave excellent activities with $\mathrm{EC}_{50}$ values of less than $2.81 \mu \mathrm{M}$ as well as SI values of over 122. However, alkyl (3b-d) or phenylamino carbonyl methyl compounds $(7 \mathbf{h}-\mathbf{i})$ did not give favorable activities because of their either low activity or high cytotoxicity. It indicated again the favorability of electron-donating substitutions on the benzene ring to the anti-HCV activity.

Then, SAR investigation was focused on the influence of the structural type of the 11-side chain while the $12 \mathrm{~N}$-benzyl/pyridylmethyl substitution was retained. In the first round, matrinic butane (9), five $1^{\prime}, 1^{\prime}$-dialkyl substituted matrinols $(\mathbf{1 0 a}-\mathbf{e})$ were designed and synthesized. Among them, benzyl derived analogues $(\mathbf{9}, \mathbf{1 0 a}-\mathbf{d})$ exhibited promising anti-HCV activities with low micro molar $\mathrm{EC}_{50}$ values ranging from 0.23 to $11.70 \mu \mathrm{M}$, as well as limited toxicity with $\mathrm{CC}_{50}$ between 12.3 and $155.8 \mu \mathrm{M}$, while the $12 N$-pyrid-4-ylmethyl derivative 10e showed a high $\mathrm{EC}_{50}$ value of $80.38 \mu \mathrm{M}$. The results indicated that 11-butane or $1^{\prime}, 1^{\prime}$-dialkyl butanol chain might not be helpful for the activity.

In the second round, to further examine the influence of saturation of 11-side chain on the activity, double bond was introduced to the $\beta, \gamma$ position of the butyl acid chain, and the corresponding methyl $\Delta^{\beta \gamma}$-matrinic crotonates $(\mathbf{1 3 a}-\mathbf{c})$ and crotonyl alcohols $(\mathbf{1 4 a}-\mathbf{b}$ and 20$)$ with 4-methoxyl, 4-fluoro, 4-nitrobenzyl substitution on the $12 \mathrm{~N}$ atom were generated respectively. As described in Table 1 , most compounds afforded very weak potencies with SI values between 10.0-24.3, inferring that the unsaturated side-chain might not be favorable for the HCV activity.

\section{PK study}

Based on above, methyl matrinates and matrinols exhibited the most potent anti-HCV activities, however, methyl matrinates might not possess favorable PK profiles in vivo owing to the exposed metabolically labile ester group. Therefore, two representative matrinols $7 \mathbf{a}$ and $\mathbf{7 b}$ were chosen to examine their PK parameters in SD rats at the single dosage of $25 \mathrm{mg} \mathrm{kg}^{-1}$ via oral route. As indicated in Table 2 and Fig. 2, both of them showed acceptable PK profiles with the areas under the curve (AUCs) of 1.58 and $2.36 \mu \mathrm{M} \cdot \mathrm{h}$ and the half-times of $4.69 \mathrm{~h}$ and $3.39 \mathrm{~h}$ respectively, indicating reasonable stabilities in vivo. Meanwhile, the results demonstrated that the concentration of compounds $7 \mathbf{a}$ and $7 \mathbf{b}$ showed a significant difference at $2 \mathrm{~h}$, owing to different dissolution rate at that time in vivo.

\section{Acute toxicity study}

The acute toxicity tests of $\mathbf{7 a}$ and $\mathbf{7 b}$ were performed in Kunming mice. Each compound was given orally in a single-dosing experiment at $250,500,750$ or $1000 \mathrm{mg} \mathrm{kg}^{-1}$, respectively. The mice were closely monitored for 7 days. As indicated in Table 3, the $\mathrm{LD}_{50}$ values for $7 \mathbf{a}$ and $\mathbf{7 b}$ were 708 and $392 \mathrm{mg} \mathrm{kg}^{-1}$, respectively, therefore, $7 \mathbf{a}$ seemed to be more promising as a parent drug from a safety prospective.

\section{Experimental \\ Instruments}

Unless otherwise noted, all commercial reagents and solvents were obtained from the commercial provider and used without further purification. Melting points (mp) were obtained with CXM-300 melting point apparatus and are uncorrected. ${ }^{1} \mathrm{H}$ NMR and ${ }^{13} \mathrm{C}$ NMR spectra were recorded on a Bruker Avance $400(400 / 101 \mathrm{MHz}$

Table 2 PK parameters of the key compounds ${ }^{a}$

\begin{tabular}{lllllll}
\hline Code & Tmax $(\mathbf{h})$ & $\mathbf{C m a x}(\boldsymbol{\mu M})$ & AUC 0-t $(\boldsymbol{\mu M ~ h})$ & AUC 0- $\boldsymbol{\infty}(\boldsymbol{\mu M ~ h )}$ & MRT (h) & t1/2 (h) \\
\hline 7a & 0.42 & 0.62 & 1.55 & 1.58 & 3.55 & 4.69 \\
$\mathbf{7 b}$ & 1.00 & 0.79 & 2.32 & 2.36 & 4.47 & 3.39 \\
\hline
\end{tabular}

a PK parameters were calculated in rats after single oral dosing of $25 \mathrm{mg} \mathrm{kg}^{-1}$, $(\mathrm{n}=3)$ by non-compartmental analysis using WinNonlin, version 5.3 


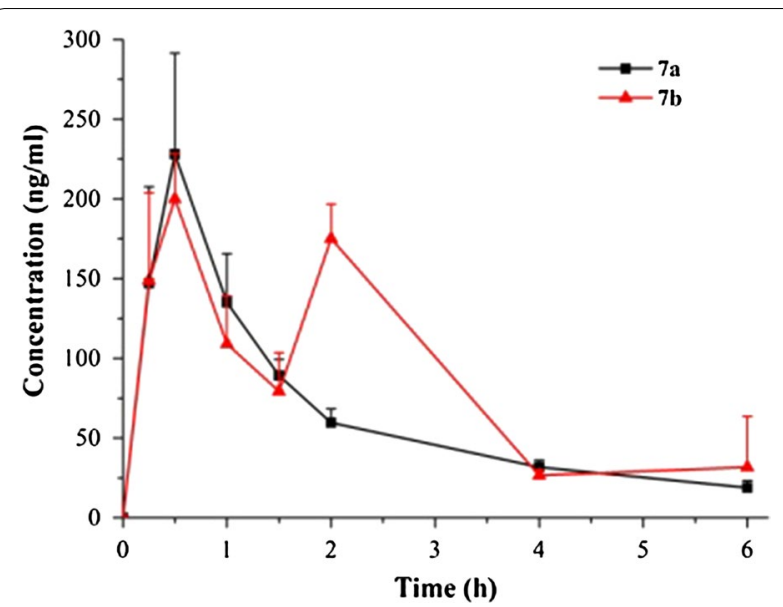

Fig. 2 Mean plasma concentration-time profiles of the key compounds ( $25 \mathrm{mg} \mathrm{kg}^{-1}$, orally)

Table 3 Acute toxicity of the key compounds

\begin{tabular}{lll}
\hline Code & $\mathbf{7 a}$ & $\mathbf{7 b}$ \\
\hline $\mathrm{LD}_{50}\left(\mathrm{mg} \mathrm{kg}^{-1}\right)$ & 708 & 392 \\
\hline
\end{tabular}

for ${ }^{1} \mathrm{H} /{ }^{13} \mathrm{C}$ ) spectrometer or Bruker Avance III 500 $\left(500 / 126 \mathrm{MHz}\right.$ for ${ }^{1} \mathrm{H} /{ }^{13} \mathrm{C}$ ) spectrometer (Varian, San Francisco, USA) respectively, in DMSO-d $\mathrm{d}_{6}$ with $\mathrm{Me}_{4} \mathrm{Si}$ as the internal standard. ESI high-resolution mass spectra (HRMS) were recorded on an AutospecUitima-TOF spectrometer (Micromass UK Ltd., Manchester, U.K.). Flash chromatography was performed on Combiflash Rf 200 (Teledyne, Nebraska, USA).

\section{General procedures for methyl $12 \mathrm{~N}$-substituted matrinate derivatives $6 a-f$}

Matrine $(5.0 \mathrm{~g}, 20.0 \mathrm{mmol})$ was added to $5 \mathrm{~N} \mathrm{NaOH}$ in water $(30 \mathrm{~mL})$, and the reaction mixture was refluxed for $9 \mathrm{~h}$, cooled in an ice bath and then acidified with $\mathrm{HCl}$ $(2 \mathrm{~N})$ to $\mathrm{pH} 6-7$. The solvent was removed in vacuo and the residue was dissolved with $2 \mathrm{~N} \mathrm{HCl}$ in methanol and then heated at refluxing for $2 \mathrm{~h}$. The solvent methanol was removed under reduced pressure to give crude $\mathbf{5}$ (5.5 g, yield 77\%), which was applied directly in the next step without further purification.

To a stirred solution of $5(10.0 \mathrm{mmol})$ and $\mathrm{K}_{2} \mathrm{CO}_{3}$ $(35.0 \mathrm{mmol})$ in chloroethane $(50 \mathrm{~mL})$, the substituted benzyl halide $(10 \mathrm{mmol})$ was added. The reaction mixture was stirred at room temperature for $5-8 \mathrm{~h}$ until TLC analysis showed completion of the reaction. Water $(20 \mathrm{~mL})$ was added to the mixture and the organic phase was separated and dried with anhydrous $\mathrm{Na}_{2} \mathrm{SO}_{4}$, concentrated, and the gained residue was purified by flash column chromatography on silica gel with $\mathrm{CH}_{2} \mathrm{Cl}_{2} /$ $\mathrm{CH}_{3} \mathrm{OH}$ as the eluent to afford the title compounds.

\section{Methyl 12N-(4-methoxybenzyl)matrinate dihydrochloride (6a)}

The title compound was prepared from 5 and 4-methoxybenzyl bromide in the same manner as described above followed by an acidification with $2 \mathrm{~N}$ hydrochloride/ ether $(10 \mathrm{~mL})$. Yield: $61 \%$; white solid; $\mathrm{mp} 208-209{ }^{\circ} \mathrm{C}$; ${ }^{1} \mathrm{H}$ NMR (500 MHz) $\delta 11.42(\mathrm{br}, 1 \mathrm{H}), 11.06$ (br, $\left.1 \mathrm{H}\right), 7.53$ (d, $J=8.7 \mathrm{~Hz}, 2 \mathrm{H}), 7.01(\mathrm{~d}, J=8.7 \mathrm{~Hz}, 2 \mathrm{H}), 4.93-4.89$ $(\mathrm{m}, 1 \mathrm{H}), 4.22-4.18(\mathrm{~m}, 1 \mathrm{H}), 4.00-3.88(\mathrm{~m}, 2 \mathrm{H}), 3.79(\mathrm{~s}$, $3 \mathrm{H}), 3.61(\mathrm{~s}, 3 \mathrm{H}), 3.58(\mathrm{~d}, J=10.4 \mathrm{~Hz}, 1 \mathrm{H}), 3.30-3.24(\mathrm{~m}$, $2 \mathrm{H}), 2.99-2.87(\mathrm{~m}, 2 \mathrm{H}), 2.68-2.65(\mathrm{~m}, 1 \mathrm{H}), 2.60-2.54(\mathrm{~m}$, $1 \mathrm{H}), 2.49-2.46(\mathrm{~m}, 3 \mathrm{H}), 2.05-1.98(\mathrm{~m}, 2 \mathrm{H}), 1.94-1.88$ (m, 1H), 1.82-1.58 (m, 8H), 1.47 (d, $J=13.7 \mathrm{~Hz}, 1 \mathrm{H})$; ${ }^{13} \mathrm{C}$ NMR $(126 \mathrm{MHz}) \delta 173.7,160.3,133.4$ (2), 122.0, 114.6 (2), 60.7, 60.6, 57.2, 55.7, 54.7, 54.6, 51.8, 48.8, 36.3, 32.9, 30.4, 28.0, 24.5, 23.9, 21.8, 18.3 (2). HRMS: calcd for $\mathrm{C}_{24} \mathrm{H}_{37} \mathrm{O}_{3} \mathrm{~N}_{2} \cdot 2 \mathrm{HCl}[\mathrm{M}-2 \mathrm{HCl}+\mathrm{H}]^{+}:$401.2799, found: 401.2790 .

\section{Methyl 12N-(4-methylbenzyl)matrinate (6b)}

The title compound was prepared from 5 and 4-methylbenzyl bromide in the same manner as described in the general procedures. Yield: 67\%; white solid; mp 89-91 ${ }^{\circ} \mathrm{C}$; ${ }^{1} \mathrm{H}$ NMR (500 MHz) $\delta 7.17(\mathrm{~d}, J=7.4 \mathrm{~Hz}, 2 \mathrm{H}), 7.10(\mathrm{~d}$, $J=7.4 \mathrm{~Hz}, 2 \mathrm{H}), 3.96(\mathrm{~d}, J=13.0 \mathrm{~Hz}, 1 \mathrm{H}), 3.55(\mathrm{~s}, 3 \mathrm{H})$, $3.01(\mathrm{~d}, J=12.9 \mathrm{~Hz}, 1 \mathrm{H}), 2.79(\mathrm{~s}, 1 \mathrm{H}), 2.72(\mathrm{~d}, J=8.6 \mathrm{~Hz}$, $1 \mathrm{H}), 2.65(\mathrm{~d}, J=9.1 \mathrm{~Hz}, 1 \mathrm{H}), 2.55(\mathrm{~d}, J=11.5 \mathrm{~Hz}, 1 \mathrm{H})$, $2.30(\mathrm{~d}, J=6.3 \mathrm{~Hz}, 1 \mathrm{H}), 2.27(\mathrm{~s}, 3 \mathrm{H}), 2.18(\mathrm{~d}, J=8.5 \mathrm{~Hz}$, $1 \mathrm{H}), \quad 1.96(\mathrm{~s}, 1 \mathrm{H}), \quad 1.85-1.24(\mathrm{~m}, 17 \mathrm{H}) ;{ }^{13} \mathrm{C}$ NMR $(126 \mathrm{MHz}) \delta 174.0,137.6,135.8,129.2$ (2), 128.9 (2), 64.3, 57.4, 57.1, 56.9, 55.4, 52.0, 51.6 (2), 37.6, 33.8, 28.4, 27.8, 27.4, 21.5, 21.2 (2), 19.0. HRMS: calcd for $\mathrm{C}_{24} \mathrm{H}_{37} \mathrm{O}_{2} \mathrm{~N}_{2}$ $[\mathrm{M}+\mathrm{H}]^{+}:$385.2850, found: 385.2844 .

\section{Methyl 12N-(4-vinylbenzyl)matrinate (6c)}

The title compound was prepared from 5 and 4-vinylbenzyl chloride in the same manner as 6b. Yield: 70\%; white solid; mp $75-77{ }^{\circ} \mathrm{C}$. ${ }^{1} \mathrm{H}$ NMR (500 MHz) $\delta 7.40$ $(\mathrm{d}, J=7.9 \mathrm{~Hz}, 2 \mathrm{H}), 7.27(\mathrm{~d}, J=7.9 \mathrm{~Hz}, 2 \mathrm{H}), 6.80-6.68$ $(\mathrm{m}, 1 \mathrm{H}), 5.79(\mathrm{~d}, J=17.7 \mathrm{~Hz}, 1 \mathrm{H}), 5.21(\mathrm{~d}, J=11.1 \mathrm{~Hz}$, $1 \mathrm{H}), 3.99(\mathrm{~d}, J=13.7 \mathrm{~Hz}, 1 \mathrm{H}), 3.54(\mathrm{~s}, 3 \mathrm{H}), 3.10-3.01(\mathrm{~m}$, $1 \mathrm{H}), 2.88-2.78(\mathrm{~m}, 1 \mathrm{H}), 2.78-2.67(\mathrm{~m}, 1 \mathrm{H}), 2.70-2.60(\mathrm{~m}$, $1 \mathrm{H}), 2.63-2.56(\mathrm{~m}, 1 \mathrm{H}), 2.29(\mathrm{t}, J=6.7 \mathrm{~Hz}, 2 \mathrm{H}), 2.18(\mathrm{~d}$, $J=8.5 \mathrm{~Hz}, 1 \mathrm{H}), 1.96(\mathrm{~s}, 1 \mathrm{H}), 1.85-1.52(\mathrm{~m}, 11 \mathrm{H}), 1.36-$ $1.24(\mathrm{~m}, 5 \mathrm{H}) ;{ }^{13} \mathrm{C}$ NMR $(126 \mathrm{MHz}) \delta 174.0,140.7,137.0$, 135.9, 129.1 (2), 126.4 (2), 114.0, 64.3, 57.4, 57.1, 56.9, 55.4, 52.2, 51.6 (2), 37.6, 33.7, 28.3, 27.9, 27.4, 21.5, 21.2, 19.0. HRMS: calcd for $\mathrm{C}_{25} \mathrm{H}_{37} \mathrm{O}_{2} \mathrm{~N}_{2}[\mathrm{M}+\mathrm{H}]^{+}:$397.2850, found: 397.2838 . 


\section{Methyl 12N-(2,4-difluorobenzyl)matrinate (6d)}

The title compound was prepared from 5 and 2,4-difluorobenzyl bromide in the same manner as $\mathbf{6 b}$. Yield: 73\%; white solid; mp 68-70 ${ }^{\circ} \mathrm{C}$; ${ }^{1} \mathrm{H}$ NMR (500 MHz) $\delta$ 7.48-7.43 (m, 1H), 7.18-7.14 (m, 1H), 7.08-7.04 (m, 1H), $3.95(\mathrm{~d}, J=13.8 \mathrm{~Hz}, 1 \mathrm{H}), 3.55(\mathrm{~s}, 3 \mathrm{H}), 3.15(\mathrm{~d}$, $J=13.7 \mathrm{~Hz}, 1 \mathrm{H}), 2.85-2.83(\mathrm{~m}, 1 \mathrm{H}), 2.72(\mathrm{~d}, J=10.7 \mathrm{~Hz}$, $1 \mathrm{H}), 2.67-2.61(\mathrm{~m}, 2 \mathrm{H}), 2.31-2.28(\mathrm{~m}, 2 \mathrm{H}), 2.23-2.05(\mathrm{~m}$, $1 \mathrm{H}), 1.96(\mathrm{~s}, 1 \mathrm{H}), 1.85-1.73(\mathrm{~m}, 4 \mathrm{H}), 1.67-1.47$ (m, 7H), 1.37-1.25 (m, 5H); ${ }^{13} \mathrm{C}$ NMR (126 MHz) $\delta 173.9,162.3$, 160.3, 132.4, 123.4, 111.7, 103.9, 64.2, 57.3, 57.1 (2), 52.1, 51.6, 47.9, 37.6, 33.7, 33.6, 28.3, 27.9, 27.3, 21.5, 21.2, 19.1. HRMS: calcd for $\mathrm{C}_{23} \mathrm{H}_{33} \mathrm{O}_{2} \mathrm{~N}_{2} \mathrm{~F}[\mathrm{M}+\mathrm{H}]^{+}$: 407.2505, found: 407.2488 .

\section{Methyl 12N-(4-nitrobenzyl)matrinate dihydrochloride (6e)}

The title compound was prepared from 5 and 4-nitrobenzyl bromide in the same manner as 6a. Yield: $75 \%$; white solid; mp 215-217 ${ }^{\circ} \mathrm{C}$; ${ }^{1} \mathrm{H}$ NMR (500 MHz) $\delta 11.87(\mathrm{br}$, $1 \mathrm{H}), 11.07$ (br, $1 \mathrm{H}), 8.52-8.52(\mathrm{~m}, 1 \mathrm{H}), 8.32-8.30(\mathrm{~m}$, $1 \mathrm{H}), 8.09(\mathrm{~d}, J=7.7 \mathrm{~Hz}, 1 \mathrm{H}), 7.77(\mathrm{t}, J=8.0 \mathrm{~Hz}, 1 \mathrm{H})$, $5.10(\mathrm{~d}, J=11.7 \mathrm{~Hz}, 1 \mathrm{H}), 4.27-4.23(\mathrm{~m}, 1 \mathrm{H}), 4.22-4.16$ $(\mathrm{m}, 1 \mathrm{H}), 4.00-3.93(\mathrm{~m}, 1 \mathrm{H}), 3.61(\mathrm{~s}, 3 \mathrm{H}), 3.60-3.56(\mathrm{~m}$, $1 \mathrm{H}), 3.35-3.10(\mathrm{~m}, 2 \mathrm{H}), 3.00-2.87(\mathrm{~m}, 2 \mathrm{H}), 2.82-2.77(\mathrm{~m}$, $1 \mathrm{H}), 2.61-2.57(\mathrm{~m}, 1 \mathrm{H}), 2.53-2.37(\mathrm{~m}, 2 \mathrm{H}), 2.12-1.51(\mathrm{~m}$, $13 \mathrm{H}) ;{ }^{13} \mathrm{C}$ NMR $(126 \mathrm{MHz}) \delta 173.7,148.3,138.7,132.2$, 130.7, 126.9, 124.8, 60.8, 60.6, 56.6, 54.6, 51.8 (2), 49.2, 36.4, 32.9, 30.5, 28.0, 24.3, 23.9, 21.9, 18.3, 18.3. HRMS: calcd for $\mathrm{C}_{23} \mathrm{H}_{34} \mathrm{O}_{4} \mathrm{~N}_{3} \cdot 2 \mathrm{HCl}[\mathrm{M}-2 \mathrm{HCl}+\mathrm{H}]^{+}:$416.2544, found: 416.2539 .

\section{Methyl 12N-(pyridin-4-ylmethyl)matrinate (6f)}

The title compound was prepared from 5 and 4-(chloromethyl)pyridine in the same manner as $\mathbf{6 b}$. Yield: $45 \%$; white solid; mp $84-86{ }^{\circ} \mathrm{C}$; ${ }^{1} \mathrm{H}$ NMR $(500 \mathrm{MHz}) \delta 8.49-$ $8.48(\mathrm{~m}, 2 \mathrm{H}), 7.32(\mathrm{~d}, J=5.9 \mathrm{~Hz}, 2 \mathrm{H}), 4.02(\mathrm{~d}, J=14.7 \mathrm{~Hz}$, $1 \mathrm{H}), 3.53(\mathrm{~s}, 3 \mathrm{H}), 3.15(\mathrm{~d}, J=14.7 \mathrm{~Hz}, 1 \mathrm{H}), 2.90-2.87(\mathrm{~m}$, $1 \mathrm{H}), 2.74-2.64(\mathrm{~m}, 3 \mathrm{H}), 2.29-2.26(\mathrm{~m}, 2 \mathrm{H}), 2.25-2.08(\mathrm{~m}$, $1 \mathrm{H}), 1.98$ (s, 1H), 1.85-1.76 (m, 4H), 1.65-1.25 (m, 12H); ${ }^{13} \mathrm{C}$ NMR (126 MHz) $\delta 173.9,150.3,149.9$ (2), 123.9 (2), 64.2, 57.3, 57.1, 56.7, 54.3, 52.6, 51.6, 37.6, 33.6, 33.5, 28.2, 27.8, 27.4, 21.5, 21.2, 19.0. HRMS: calcd for $\mathrm{C}_{22} \mathrm{H}_{34} \mathrm{O}_{2} \mathrm{~N}_{3}$ $[\mathrm{M}+\mathrm{H}]^{+}:$372.2646, found: 372.2635.

\section{General procedures for $12 \mathrm{~N}$-substituted matrinol derivativess $7 a-e$}

A solution of $\mathrm{LiAlH}_{4}(12 \mathrm{mmol})$ in anhydrous THF $(20 \mathrm{~mL})$ was added to the solution of compound 6 (10 mmol) in anhydrous THF $(3 \mathrm{~mL})$ in an ice bath, the mixture solution was then stirred at room temperature for $30 \mathrm{~min}$ before the reaction was quenched with acetone. Saturated ammonium chloride $(2 \mathrm{~mL})$ was then added and the mixture was stirred for $30 \mathrm{~min}$, and the precipitation was filtered off. The solvent was evaporated, and the residue was purified by flash column chromatography on silica gel with $\mathrm{CH}_{2} \mathrm{Cl}_{2} / \mathrm{CH}_{3} \mathrm{OH}$ as the eluent or followed by an acidification with $2 \mathrm{~N}$ hydrochloride/ether $(10 \mathrm{~mL})$ to afford target compounds.

\section{N-(4-Methoxybenzyl)matrinol dihydrochloride (7a)}

The title compound was prepared from $\mathbf{6 a}$ as described above. Yield: 82\%; white solid; mp 241-243 ${ }^{\circ} \mathrm{C} ;{ }^{1} \mathrm{H}$ NMR (400 MHz) $\delta 11.04$ (br, 1H), 10.99 (br, 1H), 7.52 $(\mathrm{d}, J=8.7 \mathrm{~Hz}, 2 \mathrm{H}), 7.02(\mathrm{~d}, J=8.7 \mathrm{~Hz}, 2 \mathrm{H}), 4.82(\mathrm{~d}$, $J=11.2 \mathrm{~Hz}, 1 \mathrm{H}), 4.36(\mathrm{~s}, 4 \mathrm{H}), 4.21-4.11(\mathrm{~m}, 1 \mathrm{H}), 4.03-$ $3.87(\mathrm{~m}, 2 \mathrm{H}), 3.79$ (s, 3H), 3.55 (d, $J=10.2 \mathrm{~Hz}, 1 \mathrm{H}), 3.27$ $(\mathrm{t}, J=13.0 \mathrm{~Hz}, 2 \mathrm{H}), 3.00-2.84(\mathrm{~m}, 2 \mathrm{H}), 2.73-2.63(\mathrm{~m}$, $1 \mathrm{H}), 2.41(\mathrm{~d}, J=11.2 \mathrm{~Hz}, 1 \mathrm{H}), 1.92(\mathrm{~d}, J=9.3 \mathrm{~Hz}, 2 \mathrm{H})$, 1.87-1.75 (m, 3H), 1.75-1.64 (m, 3H), 1.65-1.56 (m, 2H), $1.52(\mathrm{~s}, 4 \mathrm{H}) ;{ }^{13} \mathrm{C}$ NMR $(101 \mathrm{MHz}) \delta 159.9,132.9$ (2), 121.6 (2), 114.2, 60.4, 60.3, 60.1, 57.0, 55.2, 54.2, 54.2, 48.4, 36.1, 31.8, 30.0, 28.2, 24.1, 23.6, 22.7, 17.9, 17.8. HRMS: calcd for $\mathrm{C}_{23} \mathrm{H}_{37} \mathrm{O}_{2} \mathrm{~N}_{2} \cdot 2 \mathrm{HCl}[\mathrm{M}-2 \mathrm{HCl}+\mathrm{H}]^{+}: 373.2850$, found: 373.2848 .

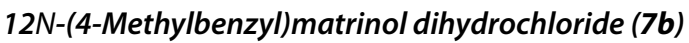

The title compound was prepared from $\mathbf{6 b}$ as described above. Yield: 85\%; white solid; mp $111-113{ }^{\circ} \mathrm{C} ;{ }^{1} \mathrm{H}$ NMR (400 MHz) $\delta 11.20(\mathrm{~s}, 1 \mathrm{H}), 11.06(\mathrm{~s}, 1 \mathrm{H}), 7.48(\mathrm{~d}$, $J=8.0 \mathrm{~Hz}, 2 \mathrm{H}), 7.26(\mathrm{~d}, J=8.0 \mathrm{~Hz}, 2 \mathrm{H}), 4.85-4.80(\mathrm{~m}$ $1 \mathrm{H}), 4.21-4.14(\mathrm{~m}, 1 \mathrm{H}), 3.99-3.89(\mathrm{~m}, 2 \mathrm{H}), 3.55(\mathrm{~d}$, $J=10.0 \mathrm{~Hz}, 1 \mathrm{H}), 3.26(\mathrm{t}, J=13.6 \mathrm{~Hz}, 2 \mathrm{H}), 3.16(\mathrm{~s}, 1 \mathrm{H})$, $2.95(\mathrm{~m}, 2 \mathrm{H}), 2.67-2.62(\mathrm{~m}, 1 \mathrm{H}), 2.55(\mathrm{~m}, 1 \mathrm{H}), 2.47-2.42$ $(\mathrm{m}, 1 \mathrm{H}), 2.33(\mathrm{~s}, 3 \mathrm{H}), 1.92-1.41(\mathrm{~m}, 16 \mathrm{H}) ;{ }^{13} \mathrm{C} \mathrm{NMR}$ (101 MHz) $\delta 138.8,131.4(2), 129.4$ (2), 126.8, 60.6, 60.2, 60.1, 57.2, 54.2, 54.2, 48.6, 36.1, 31.8, 30.0, 28.2, 24.1, 23.6, 22.7, 20.8, 17.9, 17.8. HRMS: calcd for $\mathrm{C}_{23} \mathrm{H}_{37} \mathrm{ON}_{2} \cdot 2 \mathrm{HCl}$ $[\mathrm{M}-2 \mathrm{HCl}+\mathrm{H}]^{+}:$357.2900, found: 357.2898.

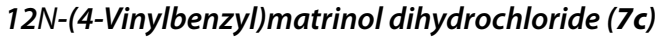

The title compound was prepared from $\mathbf{6 c}$ as described above. Yield: $75 \%$; white solid; mp $121-123{ }^{\circ} \mathrm{C}$; ${ }^{1} \mathrm{H}$ NMR (400 MHz) $\delta 11.02$ (br, 2H), 7.92-7.50 (m, 4H), 6.78 (dd, $J=17.6,10.8 \mathrm{~Hz}, 1 \mathrm{H}), 5.93(\mathrm{~d}, J=17.6 \mathrm{~Hz}, 1 \mathrm{H}), 5.34$ $(\mathrm{d}, J=11.2 \mathrm{~Hz}, 1 \mathrm{H}), 4.87(\mathrm{~d}, J=11.6 \mathrm{~Hz}, 1 \mathrm{H}), 3.54(\mathrm{~d}$, $J=10.0 \mathrm{~Hz}, 1 \mathrm{H}), 3.45(\mathrm{~m}, 2 \mathrm{H}), 3.33-3.20(\mathrm{~m}, 2 \mathrm{H}), 3.16$ (s, $1 \mathrm{H}), 3.08-2.81(\mathrm{~m}, 3 \mathrm{H}), 2.78-2.57$ (m, 2H), 2.45-2.40 $(\mathrm{m}, 1 \mathrm{H}), 2.11-1.33(\mathrm{~m}, 16 \mathrm{H}) ;{ }^{13} \mathrm{C}$ NMR $(101 \mathrm{MHz}) \delta$ 138.0, 136.0, 131.7 (2), 129.3, 126.4 (2), 115.6, 60.6, 60.2, $60.1,57.2,54.2,48.7,36.1,31.8,30.0,28.2,24.0,23.6$, 22.7, 18.6, 17.9, 17.8. HRMS: calcd for $\mathrm{C}_{24} \mathrm{H}_{37} \mathrm{ON}_{2} \cdot 2 \mathrm{HCl}$ $[\mathrm{M}-2 \mathrm{HCl}+\mathrm{H}]^{+}:$369.2900, found: 369.2900.

\section{N-(2,4-Difluorobenzyl)matrinol dihydrochloride (7d)}

The title compound was prepared from $\mathbf{6 d}$ as described above. Yield: $80 \%$; white solid, mp $124-126{ }^{\circ} \mathrm{C}$; ${ }^{1} \mathrm{H}$ NMR 
(400 MHz) $\delta 11.13(\mathrm{br}, 1 \mathrm{H}), 10.87$ (br, $1 \mathrm{H}), 7.92-7.80$ $(\mathrm{m}, 1 \mathrm{H}), 7.45-7.38(\mathrm{~m}, 1 \mathrm{H}), 7.28-7.18(\mathrm{~m}, 1 \mathrm{H}), 4.77$ $(\mathrm{d}, J=13.0 \mathrm{~Hz}, 1 \mathrm{H}), 4.28-4.08(\mathrm{~m}, 2 \mathrm{H}), 4.08-3.92(\mathrm{~m}$, $2 \mathrm{H}), 3.54(\mathrm{~d}, J=10.2 \mathrm{~Hz}, 2 \mathrm{H}), 3.28(\mathrm{t}, J=12.0 \mathrm{~Hz}, 2 \mathrm{H})$, 2.99-2.87 (m, 4H), 2.42-2.38 (m, 1H), 2.02-1.87 (m, 3H), $1.87-1.83(\mathrm{~m}, 2 \mathrm{H}), 1.79-1.68(\mathrm{~m}, 3 \mathrm{H}), 1.68-1.58(\mathrm{~m}, 3 \mathrm{H})$, $1.52(\mathrm{~s}, 4 \mathrm{H}) ;{ }^{13} \mathrm{C}$ NMR $(101 \mathrm{MHz}) \delta 135.5,132.6,113.4$, 112.1, 111.9, 104.4, 60.4, 60.1, 60.1, 54.2, 54.2, 49.8, 48.7, 36.0, 31.8, 30.0, 28.1, 23.9, 23.7, 22.4, 17.9, 17.8. HRMS: calcd for $\mathrm{C}_{22} \mathrm{H}_{33} \mathrm{ON}_{2} \mathrm{~F}_{2} \cdot 2 \mathrm{HCl}[\mathrm{M}-2 \mathrm{HCl}+\mathrm{H}]^{+}: 379.2556$, found: 379.2551 .

\section{N-(Pyridin-4-ylmethyl)matrinol dihydrochloride (7e)}

The title compound was prepared from $\mathbf{6 f}$ as described above. Yield: 77\%; white solid; mp $205-206{ }^{\circ} \mathrm{C}$; ${ }^{1} \mathrm{H}$ NMR $(400 \mathrm{MHz}) \delta 12.40(\mathrm{br}, 1 \mathrm{H}), 11.08(\mathrm{br}, 1 \mathrm{H}), 9.00(\mathrm{~d}$, $J=5.5 \mathrm{~Hz}, 2 \mathrm{H}), 8.34(\mathrm{~d}, J=5.5 \mathrm{~Hz}, 2 \mathrm{H}), 5.17(\mathrm{~s}, 1 \mathrm{H})$, $4.42-4.16(\mathrm{~m}, 2 \mathrm{H}), 3.99-3.95(\mathrm{~m}, 1 \mathrm{H}), 3.62(\mathrm{~d}, J=9.7 \mathrm{~Hz}$, $1 \mathrm{H}), 3.43(\mathrm{t}, J=5.6 \mathrm{~Hz}, 2 \mathrm{H}), 3.30-3.17(\mathrm{~m}, 3 \mathrm{H}), 2.95-$ $2.89(\mathrm{~m}, 3 \mathrm{H}), 2.71(\mathrm{~d}, J=9.8 \mathrm{~Hz}, 1 \mathrm{H}), 2.07(\mathrm{~s}, 1 \mathrm{H})$, 1.95-1.39 (m, 14H); ${ }^{13} \mathrm{C}$ NMR (101 MHz) $\delta 148.3(2)$, $143.5,129.4$ (2), 61.4, 60.6, 56.1, 54.6, 49.9,49.0, 39.6 (2), 36.5, 32.3, 30.5, 28.8, 24.2, 24.1, 23.3, 18.3. HRMS: calcd for $\mathrm{C}_{21} \mathrm{H}_{34} \mathrm{ON}_{3} \cdot 2 \mathrm{HCl}[\mathrm{M}-2 \mathrm{HCl}+\mathrm{H}]^{+}: 344.2696$, found: 344.2694.

\section{General procedures for $12 \mathrm{~N}$-substituted matrinol derivatives $7 \mathbf{f}-\mathbf{i}$}

To a stirred solution of $5(5.0 \mathrm{mmol})$ and $\mathrm{K}_{2} \mathrm{CO}_{3}$ $(17.0 \mathrm{mmol})$ in dichloroethane $(50 \mathrm{~mL})$, substituted pyridylmethyl halide or phenylcarbamic chloride $(5 \mathrm{mmol})$ was added. The reaction mixture was stirred at room temperature for $8 \mathrm{~h}$ until TLC analysis showed completion of the reaction. Water $(20 \mathrm{~mL})$ was added to the mixture and the organic phase was separated and dried with anhydrous $\mathrm{Na}_{2} \mathrm{SO}_{4}$, concentrated. To a solution of the gained residue in anhydrous THF $(3 \mathrm{~mL})$ in an ice bath, a solution of $\mathrm{LiAlH}_{4}(6 \mathrm{mmol})$ in anhydrous THF $(10 \mathrm{~mL})$ was added, the mixture solution was stirred at room temperature for $30 \mathrm{~min}$ before the reaction was quenched with acetone. The saturated ammonium chloride $(2 \mathrm{~mL})$ was then added and the mixture was stirred for $30 \mathrm{~min}$, and the precipitation was filtered off. Then the solvent was evaporated, and the residue was purified by flash column chromatography on silica gel with $\mathrm{CH}_{2} \mathrm{Cl}_{2} / \mathrm{CH}_{3} \mathrm{OH}$ as the eluent to afford the target compounds.

\section{N-(Pyridin-3-ylmethyl)matrinol (7f)}

The title compound was prepared from 5 and 3-chloromethylpyridine as described above. Yield: 43\%; yellow oil; ${ }^{1} \mathrm{H}$ NMR $\delta(500 \mathrm{MHz}) 9.13(\mathrm{~s}, 1 \mathrm{H}), 8.96(\mathrm{~d}, J=5.5 \mathrm{~Hz}$, $1 \mathrm{H}), 8.78(\mathrm{~d}, J=5.5 \mathrm{~Hz}, 1 \mathrm{H}), 8.07(\mathrm{t}, J=5.5 \mathrm{~Hz}, 1 \mathrm{H})$, 5.04-4.97(m, $1 \mathrm{H}), 4.37-4.17(\mathrm{~m}, 2 \mathrm{H}), 3.95-3.92(\mathrm{~m}, 1 \mathrm{H})$,
3.64-3.62 (m, 1H), $3.45(\mathrm{t}, J=5.9 \mathrm{~Hz}, 2 \mathrm{H}), 3.29-3.18(\mathrm{~m}$, $3 \mathrm{H}), 3.07-2.86(\mathrm{~m}, 4 \mathrm{H}), 2.68-2.66(\mathrm{~m}, 1 \mathrm{H}), 2.09-2.08(\mathrm{~m}$, $1 \mathrm{H}), 1.93-1.91(\mathrm{~m}, 2 \mathrm{H}), 1.86-1.47(\mathrm{~m}, 11 \mathrm{H}) ;{ }^{13} \mathrm{C}$ NMR $(126 \mathrm{MHz}) \delta 148.1,145.8,143.8,129.5,127.1,61.2,60.8$, 60.6, 54.6, 53.8, 49.8, 49.6, 36.6, 32.3 (2), 30.6, 28.5, 24.3, 24.1, 22.9, 18.3. HRMS: calcd for $\mathrm{C}_{21} \mathrm{H}_{34} \mathrm{ON}_{3}[\mathrm{M}+\mathrm{H}]^{+}$: 344.2696, found: 344.2694 .

\section{$12 \mathrm{~N}$-(5-Chloropyridin-2-ylmethyl)matrinol dihydrochloride (7g)}

The title compound was prepared from 5 and 5-chloro2-(chloromethyl)pyridine in the same manner as $7 \mathbf{f}$ followed by an acidification with $2 \mathrm{~N}$ hydrochloride/ether (3 mL). Yield: 48\%; light yellow solid; mp: $91-92{ }^{\circ} \mathrm{C} ;{ }^{1} \mathrm{H}$ NMR (500 MHz) $\delta 11.98$ (br, 1H), 11.06 (br, 1H), 8.61 (d, $J=2.4 \mathrm{~Hz}, 1 \mathrm{H}), 8.19(\mathrm{dd}, J=8.2,2.4 \mathrm{~Hz}, 1 \mathrm{H}), 7.64(\mathrm{~d}$, $J=8.2 \mathrm{~Hz}, 1 \mathrm{H}), 5.01-4.95(\mathrm{~m}, 1 \mathrm{H}), 4.33-4.22(\mathrm{~m}, 2 \mathrm{H})$, 3.99-3.95 (m, 1H), 3.64-3.62 (m, 1H), 3.43-3.41 (m, 2H), $3.30-3.17(\mathrm{~m}, 3 \mathrm{H}), 2.95-2.89(\mathrm{~m}, 3 \mathrm{H}), 2.71(\mathrm{~d}, J=9.8 \mathrm{~Hz}$, $1 \mathrm{H}), \quad 2.07(\mathrm{~s}, 1 \mathrm{H}), 1.97-1.35(\mathrm{~m}, 14 \mathrm{H}) ;{ }^{13} \mathrm{C}$ NMR $(126 \mathrm{MHz}) \delta 152.9,151.7,143.3,125.8,124.8,60.7,60.3$, 54.7, 53.9, 51.8, 49.2, 39.5, 36.5, 33.2, 32.9, 30.5, 28.0, 24.3, 23.9, 21.5, 18.4. HRMS: calcd for $\mathrm{C}_{21} \mathrm{H}_{33} \mathrm{ON}_{3} \mathrm{Cl} \cdot 2 \mathrm{HCl}$ $[\mathrm{M}-2 \mathrm{HCl}+\mathrm{H}]^{+}:$378.2307, found: 378.2304.

\section{N-(2-Oxo-2-(phenylamino)ethyl)matrinol (7h)}

The title compound was prepared from $\mathbf{5}$ and phenylcarbamic chloride in the same manner as 7 f. Yield: $46 \%$; white solid; mp: $136-137{ }^{\circ} \mathrm{C} ;{ }^{1} \mathrm{H}$ NMR (400 MHz) $\delta 9.64$ (br, $1 \mathrm{H}), 7.64-7.57(\mathrm{~m}, 2 \mathrm{H}), 7.31(\mathrm{t}, J=7.9 \mathrm{~Hz}, 2 \mathrm{H}), 7.06$ $(\mathrm{t}, J=7.4 \mathrm{~Hz}, 1 \mathrm{H}), 4.41-4.25(\mathrm{~m}, 1 \mathrm{H}), 3.41-3.37(\mathrm{~m}$, $2 \mathrm{H}), 3.03(\mathrm{~s}, 2 \mathrm{H}), 2.75-2.72(\mathrm{~m}, 2 \mathrm{H}), 2.44-2.31(\mathrm{~m}, 1 \mathrm{H})$, 2.00-1.93 (m, 2H), 1.85-1.76 (m, 3H), 1.70-1.48 (m, 4H), 1.47-1.20 (m, 12H); ${ }^{13} \mathrm{C}$ NMR (101 MHz) $\delta 170.1,138.9$, 131.1 (2), 123.9, 119.8 (2), 64.2, 61.2, 61.1, 57.3, 56.4, 55.7, 53.9, 37.9, 33.2, 29.7 (2), 28.7, 28.1, 27.4, 21.5, 20.8. HRMS: calcd for $\mathrm{C}_{23} \mathrm{H}_{36} \mathrm{O}_{2} \mathrm{~N}_{3}[\mathrm{M}+\mathrm{H}]^{+}:$386.2802, found: 386.2800 .

\section{$12 \mathrm{~N}$-(2-Oxo-2-((4-(trifluoromethyl)phenyl)amino)ethyl) matrinol dihydrochloride (7i)}

The title compound was prepared from 5 and 4-(trifluoromethyl)phenylcarbamic chloride in the same manner as 7 g. Yield: $62 \%$; white solid; mp: $185-187{ }^{\circ} \mathrm{C} ;{ }^{1} \mathrm{H}$ NMR (400 MHz) $\delta 11.20$ (br, 1H), 10.48 (br, 1H), 10.08 (br, $1 \mathrm{H}), 8.44(\mathrm{~d}, J=1.6 \mathrm{~Hz}, 1 \mathrm{H}), 7.56-7.46(\mathrm{~m}, 1 \mathrm{H}), 7.30$ $(\mathrm{d}, J=8.6 \mathrm{~Hz}, 1 \mathrm{H}), 4.65-4.55(\mathrm{~m}, 1 \mathrm{H}), 4.32-4.16(\mathrm{~m}$, $2 \mathrm{H}), 4.09(\mathrm{~d}, J=9.4 \mathrm{~Hz}, 1 \mathrm{H}), 3.46-3.30(\mathrm{~m}, 2 \mathrm{H}), 3.26(\mathrm{t}$, $J=9.5 \mathrm{~Hz}, 2 \mathrm{H}), 3.03-2.87(\mathrm{~m}, 2 \mathrm{H}), 2.60-2.56(\mathrm{~m}, 1 \mathrm{H})$, 2.46-2.42 (m, 1H), 1.95-1.60 (m, 12H), 1.50-1.30 (m, $6 \mathrm{H}) ;{ }^{13} \mathrm{C}$ NMR $(101 \mathrm{MHz}) \delta 164.5,152.8,127.2(2), 126.2$, 118.9 (2), 61.2, 60.7, 60.4, 56.8, 54.7, 54.6, 52.3, 36.6, 32.3, 30.7, 29.7, 29.2, 24.3, 24.1, 23.7, 18.4, 18.3. HRMS: 
calcd for $\mathrm{C}_{24} \mathrm{H}_{35} \mathrm{O}_{2} \mathrm{~N}_{3} \mathrm{~F}_{3} \cdot 2 \mathrm{HCl}[\mathrm{M}-2 \mathrm{HCl}+\mathrm{H}]^{+}: 454.2676$, found: 454.2679 .

\section{Synthesis of 12N-4-methoxybenzyl matrinic butane 9}

To a solution of $7 \mathbf{a}(5 \mathrm{mmol})$ in anhydrous $\mathrm{CH}_{2} \mathrm{Cl}_{2}$ $(20 \mathrm{~mL}), \mathrm{TsCl}(5 \mathrm{mmol}), \mathrm{TEA}(10 \mathrm{mmol})$ and dimethylamino pyridine $(0.5 \mathrm{mmol})$ were added and stirred at room temperature until the TLC showed completion of the reaction. The solution was washed successively by water $(10 \mathrm{~mL})$, saturated ammonium chloride solution $(10 \mathrm{~mL})$ and brine $(10 \mathrm{~mL})$, dried over anhydrous sodium sulfate, and concentrated to obtain crude $\mathbf{8}$. To a solution of the crude $\mathbf{8}$ in anhydrous THF, a solution of $\mathrm{LiAlH}_{4}(6 \mathrm{mmol})$ in anhydrous THF was added in an ice bath, then the mixture was stirred at room temperature for $30 \mathrm{~min}$, the reaction was then quenched with acetone, $2 \mathrm{ml}$ saturated ammonium chloride was added and stirred for $30 \mathrm{~min}$, and the precipitation was filtrated. The gained residue was purified by flash column chromatography on silica gel with $\mathrm{CH}_{2} \mathrm{Cl}_{2} / \mathrm{CH}_{3} \mathrm{OH}$ as the eluent to afford the title compound 9 as a yellow solid. Yield: 56\%; mp: $73-74{ }^{\circ} \mathrm{C} ;{ }^{1} \mathrm{H}$ NMR $(400 \mathrm{MHz}) \delta 7.22(\mathrm{~d}, J=8.8 \mathrm{~Hz}$, $2 \mathrm{H}), 6.88(\mathrm{~d}, J=8.8 \mathrm{~Hz}, 2 \mathrm{H}), 3.93-3.88(\mathrm{~m}, 1 \mathrm{H}), 3.74(\mathrm{~s}$, $3 \mathrm{H}), 3.43-3.21(\mathrm{~m}, 1 \mathrm{H}), 3.00(\mathrm{~d}, J=10.3 \mathrm{~Hz}, 1 \mathrm{H}), 2.88-$ $2.61(\mathrm{~m}, 3 \mathrm{H}), 2.53(\mathrm{~d}, J=11.7 \mathrm{~Hz}, 1 \mathrm{H}), 2.22-2.15(\mathrm{~m}, 1 \mathrm{H})$, $1.96(\mathrm{~s}, 1 \mathrm{H}), 1.90-1.73(\mathrm{~m}, 3 \mathrm{H}), 1.64(\mathrm{~s}, 2 \mathrm{H}), 1.50-1.37(\mathrm{~m}$, $12 \mathrm{H}), 0.87$ (s, 3H); ${ }^{13} \mathrm{C}$ NMR (101 MHz) $\delta$ 158.4, 129.9, $128.4,114.1$ (2), 113.9, 64.3, 63.0, 57.1, 55.5, 55.4, 55.1, 52.0, 37.8, 37.5, 33.7, 28.4, 27.5, 25.9, 23.0, 21.6, 21.2, 14.5 . HRMS: calcd for $\mathrm{C}_{23} \mathrm{H}_{37} \mathrm{ON}_{2}[\mathrm{M}+\mathrm{H}]^{+}: 357.2900$, found: 357.2899 .

\section{General procedures for $1^{\prime}, 1^{\prime}$-dialkyl-12N-substituted matrinol derivatives $10 a-e$}

To a solution of compound 6 (5 $\mathrm{mmol})$ in anhydrous THF $(10 \mathrm{~mL})$, a solution of $2 \mathrm{~N}$ alkylmagnesium chloride in THF (25 mmol) was added in an ice bath, and the mixture solution was heated at refluxing for $2 \mathrm{~h}$. After reaction completed, the reaction was quenched with a solution of saturated aqueous ammonium chloride ( $2 \mathrm{~mL}$ ). The residue was purified by flash column chromatography on silica gel with $\mathrm{CH}_{2} \mathrm{Cl}_{2} / \mathrm{CH}_{3} \mathrm{OH}$ as the eluent followed by the acidification with $2 \mathrm{~N}$ hydrochloride/ ether $(3 \mathrm{~mL})$ to afford the title compounds.

\section{1',1'-Dimethyl-12N-(4-methoxybenzyl)matrinol dihydrochloride (10a)}

The title compound was prepared from $6 \mathbf{6}$ and methylmagnesium chloride using the same method as described above. Yield: 67\%; white solid; mp: 125$127{ }^{\circ} \mathrm{C}$; ${ }^{1} \mathrm{H}$ NMR (400 MHz) $\delta 11.35$ (br, $\left.1 \mathrm{H}\right), 11.05$ (br, $1 \mathrm{H}), 7.53(\mathrm{~d}, J=8.8 \mathrm{~Hz}, 2 \mathrm{H}), 6.99(\mathrm{~d}, J=8.8 \mathrm{~Hz}, 2 \mathrm{H})$, $4.78(\mathrm{~d}, J=11.2 \mathrm{~Hz}, 1 \mathrm{H}), 4.22-4.12(\mathrm{~m}, 1 \mathrm{H}), 3.94-3.89$ (m, 2H), $3.77(\mathrm{~s}, 3 \mathrm{H}), 3.59(\mathrm{~d}, J=10.0 \mathrm{~Hz}, 1 \mathrm{H}), 3.25(\mathrm{t}$, $J=13.6 \mathrm{~Hz}, 2 \mathrm{H}), 3.00-2.87(\mathrm{~m}, 2 \mathrm{H}), 2.68-2.57(\mathrm{~m}, 2 \mathrm{H})$, $2.46(\mathrm{~d}, J=12.4 \mathrm{~Hz}, 1 \mathrm{H}), 2.02-1.51(\mathrm{~m}, 12 \mathrm{H}), 1.46-1.39$ (m, 4H), 1.11-1.07 (m, 5H); ${ }^{13} \mathrm{C}$ NMR (126 MHz) $\delta 159.8$, 132.9 (2), 121.6, 114.1 (2), 72.4, 68.7, 57.0, 55.2, 54.2, 54.1, 44.8, 42.9, 35.7, 32.3, 32.0, 29.9, 29.6, 29.2, 27.6, 25.5, 24.1, 23.6, 21.3. HRMS: calcd for $\mathrm{C}_{25} \mathrm{H}_{41} \mathrm{O}_{2} \mathrm{~N}_{2} \cdot 2 \mathrm{HCl}$ $[\mathrm{M}-2 \mathrm{HCl}+\mathrm{H}]^{+}:$401.3163, found: 401.3163 .

\section{1',1'-Dimethyl-12N-(4-methylbenzyl)matrinol dihydrochloride (10b)}

The title compound was prepared from $\mathbf{6 b}$ and methylmagnesium chloride using the same method as described above. Yield 63\%; white solid; mp: $120-122{ }^{\circ} \mathrm{C}$; ${ }^{1} \mathrm{H}$ NMR $(400 \mathrm{MHz}) \delta 11.12(\mathrm{br}, 1 \mathrm{H}), 10.98(\mathrm{br}, 1 \mathrm{H}), 7.48$ (dd, $J=8.0,5.6 \mathrm{~Hz}, 2 \mathrm{H}), 7.27(\mathrm{~d}, J=7.6 \mathrm{~Hz}, 2 \mathrm{H}), 4.91-4.74$ $(\mathrm{m}, 1 \mathrm{H}), 4.33-4.14(\mathrm{~m}, 2 \mathrm{H}), 4.04(\mathrm{~s}, 5 \mathrm{H}), 3.62-3.54(\mathrm{~m}$, $1 \mathrm{H}), 3.29-3.24(\mathrm{~m}, 2 \mathrm{H}), 2.99-2.88(\mathrm{~m}, 2 \mathrm{H}), 2.73-2.68$ $(\mathrm{m}, 1 \mathrm{H}), 2.34(\mathrm{~s}, 3 \mathrm{H}), 2.04-1.56(\mathrm{~m}, 15 \mathrm{H}), 1.49-1.42$ (m, 2H), $1.10(\mathrm{~d}, J=3.2 \mathrm{~Hz}, 2 \mathrm{H}) ;{ }^{13} \mathrm{C}$ NMR $(126 \mathrm{MHz})$ $\delta$ 132.1, 123.1 (2), 121.5 (2), 117.9, 62.3, 61.7, 53.3, 53.0, 50.1, 46.9, 41.5, 36.8, 34.4, 28.4, 23.4, 23.3, 22.9 (2), 19.9 (2), 15.9, 15.6, 11.8. HRMS: calcd for $\mathrm{C}_{25} \mathrm{H}_{41} \mathrm{ON}_{2} \cdot 2 \mathrm{HCl}$ $[\mathrm{M}-2 \mathrm{HCl}+\mathrm{H}]^{+}:$385.3213, found: 385.3214 .

\section{1',1'-Diethyl-12N-(4-methylbenzyl)matrinol dihydrochloride (10c)}

The title compound was prepared from $\mathbf{6 b}$ and ethylmagnesium chloride using the same method as described above. Yield 72\%; yellow oil; ${ }^{1} \mathrm{H}$ NMR (400 MHz) $\delta 10.91$ (br, 1H), 10.54 (br, 1H), 7.45 (d, $J=8.0 \mathrm{~Hz}, 2 \mathrm{H}), 7.29$ (d, $J=7.6 \mathrm{~Hz}, 2 \mathrm{H}), 4.85-4.80(\mathrm{~m}, 1 \mathrm{H}), 4.56-4.14(\mathrm{~m}, 3 \mathrm{H})$, 4.06-3.82 (m, 3H), 3.61-3.53 (m, 3H), 3.35-3.24 (m, 2H), $3.12-2.85(\mathrm{~m}, 3 \mathrm{H}), 2.78(\mathrm{~d}, J=6.8 \mathrm{~Hz}, 1 \mathrm{H}), 2.34(\mathrm{~s}, 3 \mathrm{H})$, 2.09-1.99 (m, 3H), 1.95-1.69 (m, 9H), 1.69-1.53 (m, $3 \mathrm{H}), 1.53-1.33(\mathrm{~m}, 2 \mathrm{H}), 0.96-0.92(\mathrm{~m}, 4 \mathrm{H}) ;{ }^{13} \mathrm{C}$ NMR (126 MHz) $\delta 138.9,131.3$ (2), 129.3 (2), 126.8, 80.6, 60.3, 60.2, 57.3, 54.2 (2), 48.9, 35.6, 32.9, 32.8, 30.0, 24.0, 23.6, 20.8 (2), 19.9, 17.8, 13.2, 12.6, 8.6 (2). HRMS: calcd for $\mathrm{C}_{27} \mathrm{H}_{45} \mathrm{ON}_{2} \cdot 2 \mathrm{HCl} \quad[\mathrm{M}-2 \mathrm{HCl}+\mathrm{H}]^{+}:$413.3526, found: 413.3524 .

\section{1',1'-Dimethyl-12N-(2,4-difluorobenzyl)matrinol dihydrochloride (10d)}

The title compound was prepared from $\mathbf{6} \mathbf{d}$ and methylmagnesium chloride using the same method as described above. Yield: $75 \%$; white solid; mp: $237-238{ }^{\circ} \mathrm{C}$; ${ }^{1} \mathrm{H}$ NMR $(400 \mathrm{MHz}) \delta 11.02(\mathrm{~s}, 1 \mathrm{H}), 10.40(\mathrm{~s}, 1 \mathrm{H}), 7.93-7.81$ $(\mathrm{m}, 1 \mathrm{H}), 7.47-7.40(\mathrm{~m}, 1 \mathrm{H}), 7.29-7.19(\mathrm{~m}, 1 \mathrm{H}), 4.78$ $(\mathrm{d}, J=13.2 \mathrm{~Hz}, 1 \mathrm{H}), 4.30-4.20(\mathrm{~m}, 1 \mathrm{H}), 4.20-4.05(\mathrm{~m}$, $1 \mathrm{H}), 4.10-3.85(\mathrm{~m}, 1 \mathrm{H}), 3.53(\mathrm{~d}, J=8.4 \mathrm{~Hz}, 3 \mathrm{H}), 3.29(\mathrm{t}$, $J=12.0 \mathrm{~Hz}, 2 \mathrm{H}), 3.06-2.82(\mathrm{~m}, 4 \mathrm{H}), 2.00-1.51(\mathrm{~m}, 11 \mathrm{H})$, $1.47-1.44(\mathrm{~m}, 3 \mathrm{H}), 1.11(\mathrm{~d}, J=3.6 \mathrm{~Hz}, 6 \mathrm{H}) ;{ }^{13} \mathrm{C}$ NMR 
$(126 \mathrm{MHz}) \delta 164.2,162.2,135.6,113.5,112.0,104.3$, 68.6, 60.5, 60.1, 54.2 (2), 49.8, 48.8, 42.9, 35.9, 29.9, 29.5, 29.2, 28.7, 23.9, 23.7, 20.4, 17.8 (2). HRMS: calcd for $\mathrm{C}_{24} \mathrm{H}_{37} \mathrm{ON}_{2} \mathrm{~F}_{2} \cdot 2 \mathrm{HCl}[\mathrm{M}-2 \mathrm{HCl}+\mathrm{H}]^{+}:$407.2868, found: 407.2863 .

\section{1',1'-Dimethyl-12N-(4-pyridylmethyl)matrinol (10e)}

The title compound was prepared from $\mathbf{6 f}$ and methylmagnesium chloride using the same method as described above without acidification. Yield: $68 \%$; yellow solid; mp: 243-245 ${ }^{\circ} \mathrm{C}$; ${ }^{1} \mathrm{H}$ NMR (400 MHz) $\delta 8.47(\mathrm{~d}, J=5.6 \mathrm{~Hz}$, $2 \mathrm{H}), 7.33(\mathrm{~d}, J=5.6 \mathrm{~Hz}, 2 \mathrm{H}), 4.02(\mathrm{~s}, 1 \mathrm{H}), 3.94(\mathrm{~d}$, $J=15.2 \mathrm{~Hz}, 1 \mathrm{H}), 3.32(\mathrm{~s}, 1 \mathrm{H}), 3.19(\mathrm{~d}, J=14.4 \mathrm{~Hz}, 1 \mathrm{H})$, 2.89 (d, $J=8.4 \mathrm{~Hz}, 1 \mathrm{H}), 2.72(\mathrm{t}, J=11.2 \mathrm{~Hz}, 3 \mathrm{H}), 2.17$ $(\mathrm{d}, J=8.8 \mathrm{~Hz}, 1 \mathrm{H}), 2.00(\mathrm{~s}, 1 \mathrm{H}), 1.81(\mathrm{~d}, J=12.0 \mathrm{~Hz}$, $3 \mathrm{H}), 1.64-1.54(\mathrm{~m}, 4 \mathrm{H}), 1.42-1.24(\mathrm{~m}, 10 \mathrm{H}), 1.01(\mathrm{~d}$, $J=2.8 \mathrm{~Hz}, 6 \mathrm{H}) ;{ }^{13} \mathrm{C}$ NMR $(126 \mathrm{MHz}) \delta 149.7,149.4$ (2), 123.3 (2), 68.7, 63.8, 56.5, 56.4, 53.7, 51.9, 43.9, 37.0, 34.7, 32.7, 29.4, 29.1, 29.0, 27.4, 26.7, 20.8, 20.5, 18.1. HRMS: calcd for $\mathrm{C}_{23} \mathrm{H}_{38} \mathrm{ON}_{3}[\mathrm{M}+\mathrm{H}]^{+}: 372.3009$, found: 372.3008 .

\section{General procedures for methyl (Z)-12N-substituted $\Delta^{\beta} \mathrm{v}_{\text {-matrinic crotonate derivatives } 13 \mathrm{a}-\mathrm{c}}$}

Lehmannine $(3.0 \mathrm{~g}, 12.2 \mathrm{mmol})$ was added to a solution of $5 \mathrm{~N} \mathrm{HCl}(30 \mathrm{~mL})$. The reaction mixture was heated at reflux for $9 \mathrm{~h}$. The solvent was then removed in vacuo, and the residue was recrystallized by methanol and ethyl acetate to afford the intermediate $\mathbf{1 1}(2.5 \mathrm{~g}, 60 \%)$ as white solid. mp: $191-193{ }^{\circ} \mathrm{C}$. ${ }^{1} \mathrm{H}$ NMR (400 MHz) $\delta 12.39$ (s, $1 \mathrm{H}), 11.21(\mathrm{~d}, J=8.0 \mathrm{~Hz}, 1 \mathrm{H}), 10.27(\mathrm{~d}, J=9.3 \mathrm{~Hz}, 1 \mathrm{H})$, $9.30(\mathrm{~d}, J=9.0 \mathrm{~Hz}, 1 \mathrm{H}), 6.01(\mathrm{dt}, J=10.8,7.3 \mathrm{~Hz}, 1 \mathrm{H})$, $5.49(\mathrm{t}, J=10.4 \mathrm{~Hz}, 1 \mathrm{H}), 5.04-4.92(\mathrm{~m}, 1 \mathrm{H}), 3.99-3.764$ $(\mathrm{m}, 1 \mathrm{H}), 3.65(\mathrm{~d}, J=10.1 \mathrm{~Hz}, 1 \mathrm{H}), 3.44-3.33(\mathrm{~m}, 2 \mathrm{H})$, 3.25-3.20 (m, 2H), 3.20-3.02 (m, 1H), 2.97-2.89 (m, $2 \mathrm{H}), 2.55-2.51(\mathrm{~m}, 1 \mathrm{H}), 2.40-2.23(\mathrm{~m}, 1 \mathrm{H}), 1.89-1.56$ $(\mathrm{m}, 8 \mathrm{H}) ;{ }^{13} \mathrm{C}$ NMR $(101 \mathrm{MHz}) \delta 172.4,132.4,125.7,60.4$, 54.8, 54.7, 49.8, 41.5, 35.5, 33.8, 30.8, 24.6, 23.6, 18.5(2); HRMS: calcd for $\mathrm{C}_{15} \mathrm{H}_{25} \mathrm{~N}_{2} \mathrm{O}_{2} \cdot 2 \mathrm{HCl}[\mathrm{M}-2 \mathrm{HCl}+\mathrm{H}]^{+}$: 265.1911, found: 265.1909.

Compound 11 (1.0 g, $3.0 \mathrm{mmol})$ was dissolved in $2 \mathrm{~N}$ $\mathrm{MeOH} / \mathrm{HCl}(30 \mathrm{~mL})$, and the reaction mixture was refluxed for 2 h. Compound 12 was obtained by evaporation and used in the next reaction without further purification. Anhydrous $\mathrm{K}_{2} \mathrm{CO}_{3}$ (3.5 equiv) and substituted benzyl bromide (1.5 equiv) were added to a solution of compound 12 in acetonitrile $(30 \mathrm{~mL})$, and the reaction solution was then stirred at room temperature until TLC analysis showed completion of the reaction. The reaction mixture was filtered, and the filtrate was washed by water and brine, dried with anhydrous $\mathrm{Na}_{2} \mathrm{SO}_{4}$, filtrated, and concentrated to afford crude compound 13 . The title compounds were obtained by purifying with flash column chromatography on silica gel with dichloromethane and methanol as the eluent.

\section{(Z)-Methyl 12N-(4-methoxybenzyl)- $\Delta^{\beta \mathrm{v}}$-matrinic crotonate (13a)}

The title compound was prepared from 12 and 4-methoxybenzyl bromide using the same method as described above. Yield: $62 \%$; white solid; mp: $98-100{ }^{\circ} \mathrm{C} .{ }^{1} \mathrm{H}$ NMR $(400 \mathrm{MHz}) \delta 7.14(\mathrm{~d}, J=8.4 \mathrm{~Hz}, 2 \mathrm{H}), 6.84(\mathrm{~d}, J=8.4 \mathrm{~Hz}$, $2 \mathrm{H}), 5.81-5.75(\mathrm{~m}, 1 \mathrm{H}), 5.33(\mathrm{t}, J=10.4 \mathrm{~Hz}, 1 \mathrm{H}), 3.92(\mathrm{~d}$, $J=13.2 \mathrm{~Hz}, 1 \mathrm{H}), 3.73(\mathrm{~s}, 3 \mathrm{H}), 3.61(\mathrm{~s}, 3 \mathrm{H}), 3.34-3.15(\mathrm{~m}$, $3 \mathrm{H}), 2.89-2.86(\mathrm{~m}, 1 \mathrm{H}), 2.72-2.75(\mathrm{~m}, 2 \mathrm{H}), 2.51-2.44(\mathrm{~m}$, $1 \mathrm{H}), 2.21-2.18(\mathrm{~m}, 1 \mathrm{H}), 1.98(\mathrm{~s}, 1 \mathrm{H}), 1.84-1.75(\mathrm{~m}, 2 \mathrm{H})$, $1.65-1.24(\mathrm{~m}, 10 \mathrm{H}) ;{ }^{13} \mathrm{C}$ NMR $(126 \mathrm{MHz}) \delta 171.3,158.0$, 136.0, 131.5, 129.7 (2), 124.8, 113.4 (2), 62.5, 58.2, 56.8, 56.7, 54.9 (2), 51.6 (2), 50.8, 34.7, 33.3, 28.1, 26.8, 21.4, 21.2. HRMS: calcd for $\mathrm{C}_{24} \mathrm{H}_{35} \mathrm{~N}_{2} \mathrm{O}_{3}[\mathrm{M}+\mathrm{H}]^{+}:$399.2642, found: 399.2642 .

\section{(Z)-Methyl 12N-(4-fluorobenzyl)- $\Delta^{\beta \gamma_{-}}$-matrinic crotonate dihydrochloride (13b)}

The title compound was prepared from 12 and 4-fluorobenzyl bromide using the same method as described above. Yield: 68\%; white solid; mp: 151$153{ }^{\circ} \mathrm{C}$. MS-ESI m/s: 387; ${ }^{1} \mathrm{H}$ NMR (400 MHz) $\delta$ $11.93(\mathrm{~d}, J=8.0 \mathrm{~Hz}, 1 \mathrm{H}), 11.08(\mathrm{~d}, J=7.6 \mathrm{~Hz}, 1 \mathrm{H})$, 7.64-7.61 (m, 2H), 7.32-7.27 (m, 2H), 6.27-6.20 (m, $1 \mathrm{H}), 5.88-5.78(\mathrm{~m}, 1 \mathrm{H}), 5.28(\mathrm{t}, J=11.2 \mathrm{~Hz}, 1 \mathrm{H}), 4.63$ $(\mathrm{d}, J=12.0 \mathrm{~Hz}, 1 \mathrm{H}), 4.00-3.85(\mathrm{~m}, 2 \mathrm{H}), 3.68-3.17(\mathrm{~m}$, 9H), 3.00-2.79 (m, 3H), $2.63(\mathrm{~s}, 1 \mathrm{H}), 1.83-1.56(\mathrm{~m}, 8 \mathrm{H})$; ${ }^{13} \mathrm{C}$ NMR $(126 \mathrm{MHz}) \delta 170.7,161.7,133.7,133.6,133.2$, $126.0,124.9,115.9,115.8,59.6,58.6,56.7,54.2,54.1$, 51.9, 47.3, 35.1, 33.3, 30.2, 24.0, 23.9, 18.0, 17.9. HRMS: calcd for $\mathrm{C}_{23} \mathrm{H}_{32} \mathrm{FN}_{2} \mathrm{O}_{2} \cdot 2 \mathrm{HCl}[\mathrm{M}-2 \mathrm{HCl}+\mathrm{H}]^{+}: 387.2442$, found: 387.2446 .

\section{(Z)-Methyl 12N-(3-nitrobenzyl)- $\Delta^{\beta \mathrm{v}}$-matrinic crotonate dihydrochloride (13c)}

The title compound was prepared from 12 and 3-nitrobenzyl bromide using the same method as described above. Yield: $70 \%$; white solid; mp: $185-187^{\circ} \mathrm{C}$; ${ }^{1} \mathrm{H}$ NMR (400 MHz) $\delta 12.33(\mathrm{~s}, 1 \mathrm{H}), 11.07$ (s, 1H), 8.41 (s, $1 \mathrm{H}), 8.26(\mathrm{~d}, J=8.4 \mathrm{~Hz}, 1 \mathrm{H}), 8.02(\mathrm{~d}, J=7.5 \mathrm{~Hz}, 1 \mathrm{H}), 7.71$ $(\mathrm{t}, J=8.0 \mathrm{~Hz}, 1 \mathrm{H}), 6.22(\mathrm{dt}, J=15.1,7.5 \mathrm{~Hz}, 1 \mathrm{H}), 5.84(\mathrm{t}$, $J=10.6 \mathrm{~Hz}, 1 \mathrm{H}), 5.39-5.21(\mathrm{~m}, 1 \mathrm{H}), 4.70(\mathrm{~d}, J=12.9 \mathrm{~Hz}$, $1 \mathrm{H}), 4.15-3.78(\mathrm{~m}, 3 \mathrm{H}), 3.64(\mathrm{~s}, 3 \mathrm{H}), 3.47-3.41(\mathrm{~m}, 1 \mathrm{H})$, $3.26(\mathrm{~d}, J=11.7 \mathrm{~Hz}, 2 \mathrm{H}), 2.99-2.83(\mathrm{~m}, 3 \mathrm{H}), 2.61(\mathrm{~s}, 1 \mathrm{H})$, 2.56-2.48 (m, 1H), 1.80-1.76 (m, 2H), 1.70-1.49 (m, 7H); ${ }^{13} \mathrm{C}$ NMR $(126 \mathrm{MHz}) \delta 170.7,147.8,138.1,133.4,131.6$, 130.4, 126.3, 124.9, 124.4, 59.6, 58.7, 56.5, 54.3, 54.1, 51.9, 47.7, 35.2, 33.3, 30.3, 23.9, 23.9, 18.0, 17.9. HRMS: calcd for $\mathrm{C}_{23} \mathrm{H}_{32} \mathrm{~N}_{3} \mathrm{O}_{4} \cdot 2 \mathrm{HCl}[\mathrm{M}-2 \mathrm{HCl}+\mathrm{H}]^{+}:$414.2387, found: 414.2391. 


\section{General procedures for $(Z)-12 N$-substituted $\Delta^{\beta v}$-matrinic crotonol derivatives $\mathbf{1 4 a - b}$}

A solution of the $\mathrm{LiAlH}_{4}$ in THF $(2.4 \mathrm{~N}, 1.2$ equiv) was added to the solution of compound $\mathbf{1 3}$ in anhydrous THF in ice bath, then the mixture solution was stirred at room temperature for $30 \mathrm{~min}$, the reaction was then quenched with acetone, $2 \mathrm{~mL}$ saturated ammonium chloride solution was added and stirred for $30 \mathrm{~min}$, and the precipitation was filtrated off. The filtrate was concentrated, and the residue was purified by flash column chromatography on silica gel with dichloromethane and methanol as the eluent followed by the acidification by $2 \mathrm{~N}$ hydrochloride/ether to afford compounds.

\section{(Z)-12N-(4-Methoxybenzyl)-- ${ }^{\beta \mathrm{V}}{ }_{\text {-matrinic crotonol }}$ dihydrochloride (14a)}

The title compound was prepared from 13a using the same method as described above. Yield: $86 \%$; white solid; mp: $175-177{ }^{\circ} \mathrm{C} ;{ }^{1} \mathrm{H}$ NMR (400 MHz) $\delta 11.46$ (br, $1 \mathrm{H}$ ), $11.15(\mathrm{br}, 1 \mathrm{H}), 7.48-7.45(\mathrm{~d}, J=8.8 \mathrm{~Hz}, 2 \mathrm{H}), 7.01-6.99(\mathrm{~d}$, $J=8.8 \mathrm{~Hz}, 2 \mathrm{H}), 6.17-6.11(\mathrm{~m}, 1 \mathrm{H}), 5.68(\mathrm{t}, J=10.8 \mathrm{~Hz}$, $1 \mathrm{H}), 5.16(\mathrm{dd}, J=10.4 \mathrm{~Hz}, 1 \mathrm{H}), 4.66(\mathrm{~d}, J=11.6 \mathrm{~Hz}$, $1 \mathrm{H}), 4.02-3.93(\mathrm{~m}, 1 \mathrm{H}), 3.89-3.78(\mathrm{~m}, 1 \mathrm{H}), 3.74(\mathrm{~s}, 3 \mathrm{H})$, 3.69-3.43 (m, 5H), 3.39-3.28 (m, 3H), 2.99-2.88 (m, $2 \mathrm{H})$, 2.78-2.75 (m, 1H), 2.55-2.49 (m, 1H), 2.37-2.31 (m, 1H), $1.89-1.53(\mathrm{~m}, 8 \mathrm{H}) ;{ }^{13} \mathrm{C}$ NMR $(126 \mathrm{MHz}) \delta 159.9,139.2$, 132.8 (2), 123.5, 121.6, 114.2 (2), 59.8, 59.7, 58.6, 57.1, 55.2 (2), 54.2, 47.1, 35.3, 31.8, 30.2, 24.2, 24.0, 18.0, 17.9. HRMS: calcd for $\mathrm{C}_{23} \mathrm{H}_{35} \mathrm{~N}_{2} \mathrm{O}_{2} \cdot 2 \mathrm{HCl}[\mathrm{M}-2 \mathrm{HCl}+\mathrm{H}]^{+}$: 371.2693, found: 371.2698 .

\section{(Z)-12N-4-(Fluorobenzyl)-- $\Delta^{\beta \mathrm{\gamma}}$-matrinic crotonol dihydrochloride (14b)}

The title compound was prepared from $\mathbf{1 3 b}$ using the same method as described above. Yield: 87\%; white solid; mp: $194-196{ }^{\circ} \mathrm{C} ;{ }^{1} \mathrm{H}$ NMR $(400 \mathrm{MHz}) \delta 11.77$ (br, $1 \mathrm{H}), 11.15(\mathrm{br}, 1 \mathrm{H}), 7.64(\mathrm{dd}, J=5.6 \mathrm{~Hz}, 2 \mathrm{H}), 7.28(\mathrm{t}$, $J=8.8 \mathrm{~Hz}, 2 \mathrm{H}), 6.18-6.11(\mathrm{~m}, 1 \mathrm{H}), 5.71(\mathrm{t}, J=10.8 \mathrm{~Hz}$, $1 \mathrm{H}), 5.18(\mathrm{dd}, J=10.8 \mathrm{~Hz}, 1 \mathrm{H}), 4.70(\mathrm{~d}, J=12.4 \mathrm{~Hz}, 1 \mathrm{H})$, 4.04-3.87 (m, 2H), 3.77-3.41 (m, 5H), 3.41-3.28 (m, 2H), $3.00-2.76(\mathrm{~m}, 3 \mathrm{H}), 2.58-2.51(\mathrm{~m}, 2 \mathrm{H}), 2.37-2.29(\mathrm{~m}, 1 \mathrm{H})$, $1.90-1.56(\mathrm{~m}, 8 \mathrm{H}) ;{ }^{13} \mathrm{C}$ NMR $(126 \mathrm{MHz}) \delta$ 163.6, 139.4, 133.7, 133.6, 126.2, 123.4, 115.9, 115.7, 59.8, 59.6, 58.8, 56.7, 54.2 (2), 47.3, 35.3, 31.8, 30.2, 24.1, 24.0, 18.0, 17.9. HRMS: calcd for $\mathrm{C}_{22} \mathrm{H}_{32} \mathrm{FN}_{2} \mathrm{O} \cdot 2 \mathrm{HCl}[\mathrm{M}-2 \mathrm{HCl}+\mathrm{H}]^{+}$: 359.2493, found: 359.2492 .

\section{Synthesis of (Z)-12N-(3-nitrobenzyl)- $\Delta^{\beta v}$-matrinic crotonol dihydrochloride 20}

The compound 12 (1.0 g, $4.0 \mathrm{mmol})$ was dissolved in $2 \mathrm{~N} \mathrm{HCl} / \mathrm{MeOH}(30 \mathrm{~mL})$. The reaction mixture was refluxed for $2 \mathrm{~h}$, then anhydrous $\mathrm{K}_{2} \mathrm{CO}_{3}$ (3.5 equiv) and
$\mathrm{Boc}_{2} \mathrm{O}$ (1.5 equiv) were added to the reaction solution, and the mixture solution was stirred at room temperature until TLC analysis showed completion of the reaction. The reaction mixture was filtered, and the filtrate was washed by water and brine, dried with anhydrous $\mathrm{Na}_{2} \mathrm{SO}_{4}$, filtrated and concentrated to afford the crude 15.

A solution of the $\mathrm{LiAlH}_{4}$ in THF (2.4 N, 1.2 equiv) was added to the solution of compound 15 in anhydrous THF in ice-bath, then the mixture solution was stirred at room temperature for $30 \mathrm{~min}$, the reaction was then quenched with acetone, $2 \mathrm{~mL}$ saturated ammonium chloride solution was added and stirred for $30 \mathrm{~min}$, and the precipitation was filtrated off. The filtrate was concentrated, and the residue of compound $\mathbf{1 6}$ was dissolved in ethyl acetate, and washed with water and brine, dried with anhydrous $\mathrm{Na}_{2} \mathrm{SO}_{4}$, filtrated and concentrated. The residue was stirred in $2 \mathrm{~N} \mathrm{HCl} / \mathrm{Et}_{2} \mathrm{O}(20 \mathrm{~mL})$ to remove the Boc protection group, then the mixute was filtrated to give the crude 17.

The crude 17 (1.0 equiv), TBSCl (1.2 equiv) and imidazole (1.5 equiv) were used to synthesize compound 18 in $\mathrm{CH}_{2} \mathrm{Cl}_{2}$, after reaction was complete, 3-nitrobenzyl bromide (3.0 equiv) and TEA (3.0 equiv) were added to the reaction solution, which was stirred at room temperature until TLC analysis showed completion of the reaction. The reaction solution was washed by water and brine, dried over anhydrous $\mathrm{Na}_{2} \mathrm{SO}_{4}$, filtrated and concentrated to afford the crude compound 19.

The crude 19 was dissolved in $2 \mathrm{~N} \mathrm{HCl}(15 \mathrm{~mL})$, and the mixture was stirred until TLC analysis showed completion of the reaction. The $\mathrm{pH}$ of the reaction solution was then adjusted to 7-8 by addition of ammonium hydroxide. The solvent was removed under reduced pressure, and the residue was dissolved in $\mathrm{MeOH}$ and filtered to remove the organic salts. The solution was concentrated, and the residue was purified by flash column chromatography on silica gel with dichloromethane and methanol as the eluent to afford compound $\mathbf{2 0}$ as white solid. Yield: $30 \%$; mp: $143-145{ }^{\circ} \mathrm{C} ;{ }^{1} \mathrm{H}$ NMR $(400 \mathrm{MHz}) \delta 12.8$ (br, $1 \mathrm{H}), 11.17(\mathrm{br}, 1 \mathrm{H}), 8.44(\mathrm{~s}, 1 \mathrm{H})$, $8.30(\mathrm{~d}, J=8.0 \mathrm{~Hz}, 1 \mathrm{H}), 8.06(\mathrm{~d}, J=8.0 \mathrm{~Hz}, 1 \mathrm{H}), 7.75(\mathrm{t}$, $J=8.0 \mathrm{~Hz}, 1 \mathrm{H}), 6.20-6.14(\mathrm{~m}, 1 \mathrm{H}), 5.73(\mathrm{t}, J=10.4 \mathrm{~Hz}$, $1 \mathrm{H}), 5.27-5.20(\mathrm{~m}, 1 \mathrm{H}), 4.85(\mathrm{~d}, J=12.8 \mathrm{~Hz}, 1 \mathrm{H}), 4.10$ $4.02(\mathrm{~m}, 3 \mathrm{H}), 3.65(\mathrm{~d}, J=10.4 \mathrm{~Hz}, 1 \mathrm{H}), 3.57-3.49(\mathrm{~m}$, $2 \mathrm{H}), 3.29(\mathrm{~d}, J=12.0 \mathrm{~Hz}, 2 \mathrm{H}), 3.00-2.88(\mathrm{~m}, 3 \mathrm{H}), 2.60-$ $2.53(\mathrm{~m}, 3 \mathrm{H}), 2.37-2.32(\mathrm{~m}, 1 \mathrm{H}), 1.91-1.56(\mathrm{~m}, 8 \mathrm{H})$; ${ }^{13} \mathrm{C}$ NMR $(126 \mathrm{MHz}) \delta 147.8,139.7,138.0,131.9,130.4$, 126.3, 124.3, 123.3, 59.8, 59.6, 58.9, 56.5, 54.2, 47.6, 35.3, 31.8, 30.3, 29.2, 24.1, 23.9, 18.0, 17.9. HRMS: calcd for $\mathrm{C}_{22} \mathrm{H}_{32} \mathrm{~N}_{3} \mathrm{O}_{3} \cdot 2 \mathrm{HCl} \quad[\mathrm{M}-2 \mathrm{HCl}+\mathrm{H}]^{+}: \quad 386.2438$, found: 386.2440 . 


\section{Biology assay Cell culture}

Human liver cell line Huh7.5 cells (kindly provided by Vertex Pharmaceuticals, Inc., Boston, MA) were cultured in Dulbecco's modified eagle medium (DMEM) supplemented with $10 \%$ inactivated fetal bovine serum and $1 \%$ penicillin-streptomycin (invitrogen). Cells were digested with $0.05 \%$ trypsin-ethylene diamine tetraacetic acid (EDTA) and split twice a week.

\section{Anti-HCV effect in vitro}

Huh7.5 cells were seeded into 96-well or 6-well plates (Costar) at a density of $3 \times 10^{4}$ cells cm${ }^{-2}$. After $24 \mathrm{~h}$ incubation, the cells were infected with $\mathrm{HCV}$ viral stock (45 IU cell ${ }^{-1}$ ) and simultaneously treated with the test compounds at various concentrations or solvent as control. The culture medium was removed after $72 \mathrm{~h}$ inoculation, the intracellular total RNA (in 96-well plates) was extracted with RNeasy Mini Kit (Qiagen), and total intracellular proteins (in 6-well plates) were extracted with Cyto-Buster Protein Extraction Reagent added with $1 \mathrm{mM}$ protease inhibitor cocktail. The intracellular $\mathrm{HCV}$ RNA was quantified with a real time one-step reversetranscription polymerase chain reaction (RT-PCR).

\section{Cytotoxicity assay}

Huh7.5 cells were seeded into 96-well plates (Costar) at a density of $3 \times 10^{4}$ cells $\mathrm{cm}^{-2}$. After $24 \mathrm{~h}$ incubation, fresh culture medium containing test compounds at various concentrations were added. $72 \mathrm{~h}$ later, cytotoxicity was evaluated with 3-(4,5-dimethylthiazol-2-yl)-2,5-diphenyltetrazolium bromide (MTT).

\section{PK studies}

Three male SD mice were used in each study. Each of them was dosed with a tested compound at $25 \mathrm{mg} \mathrm{kg}^{-1}$ via oral administration. Eight blood samples were respectively collected at $0,0.25,0.5,1.0,2.0,4.0$, and $6.0 \mathrm{~h}$ and were immediately centrifuged to separate the plasma fractions. The separated plasma samples were stored at $-20{ }^{\circ} \mathrm{C}$ for analysis. Concentration-versus-time profiles were obtained for each analyte, and standard noncompartmental analysis was performed on the data using WinNonlin software, version 5.3, to recover the AUC and other non-compartmental parameters.

\section{Acute toxicity}

Female Kunming mice with weight of $20.0 \pm 1.0$ g were fed with regular rodent chow and housed in an air conditioned room. The mice were randomly divided into different groups with six mice each. Each compound was given orally in a single-dosing experiment at $0,250,500$, 750 or $1000 \mathrm{mg} \mathrm{kg}^{-1}\left(\mathrm{ddH}_{2} \mathrm{O}\right.$ as control), respectively.
The mice were closely monitored for 7 days. Body weight as well as survival was monitored.

\section{Conclusion}

In conclusion, 32 compounds (of which 27 were novel) with diverse structures, including methyl matrinate, matrinols, matrinic butane, $1^{\prime}$, 1'-dialkylmatrinols, $(Z)$ methyl $\Delta^{\beta \gamma}$-matrinic crotonates, $(Z)-\Delta^{\beta \gamma}$-matrinic crotonols were synthesized and evaluated for their anti-HCV activities, taking compound $\mathbf{1}$ as the lead. The SAR study indicated that the introduction of electron-donating substitutions on the benzene ring was helpful for the anti$\mathrm{HCV}$ activity, and the unsaturated 11-side chain might not be favorable for the activity. Out of the gathered compounds, matrinol $7 \mathbf{a}$ demonstrated a potential anti-HCV effect with the SI value of 136 . Further study showed that compound 7 a possessed reasonable PK and safety profiles in vivo, indicating a fair druggability nature. Besides, the free hydroxyl arm in 7a would make it possible to be a parent structure to make pro-drug candidates for their potential in the treatment of $\mathrm{HCV}$ infection. This study provided powerful information on further strategic optimization and development of this kind of compounds into a novel family of anti-HCV agents.

\section{Authors' contributions}

The current study is an outcome of the constructive discussion with DQS and YXW, who offered necessary guidance to ST, YHL and XZ to carry out their synthesis and characterization experiments. ZGP and TS performed the biological assay against $\mathrm{HCV}, \mathrm{XYC}$ carried out the ${ }^{1} \mathrm{H}$ NMR and ${ }^{13} \mathrm{C}$ NMR spectral analyses and HRMS analysis. JDJ provided theoretical guidance. All authors read and approved the final manuscript.

\section{Acknowledgements}

This work was supported by the National Natural Science Foundation of China (21472246), the Beijing Natural Science Foundation (7152097) and CAMS Innovation Fund for Medical Sciences (CIFMS, 2016-12 M-3-009).

\section{Competing interests}

The authors declare that they have no competing interests.

\section{Publisher's Note}

Springer Nature remains neutral with regard to jurisdictional claims in published maps and institutional affiliations.

Received: 8 December 2016 Accepted: 22 September 2017

Published online: 29 September 2017

References

1. World Health Organization Fact sheet No. 164. http://www.who.int/ mediacentre/factsheets/fs164/en/. Accessed 28 Nov 2016

2. Mohd HK, Groeger J, Flaxman AD, Wiersma ST (2013) Global epidemiology of hepatitis $C$ virus infection: new estimates of age-specific antibody to HCV seroprevalence. Hepatology 57:1333-1342

3. Gonzalez-Grande R, Jimenez-Perez M, Gonzalez AC, Mostazo TJ (2016) New approaches in the treatment of hepatitis C. World J Gastroenterol 22:1421-1432

4. Esposito I, Trinks J, Soriano V (2016) Hepatitis C virus resistance to the new direct-acting antivirals. Expert Opin Drug Metab Toxicol 12:1197-1209 
5. Kan H, Imamura M, Uchida T, Hiraga N, Hayes CN, Tsuge M, Abe H, Aikata H, Makokha GN, Chowdhury S et al (2016) Protease inhibitor resistance remains even after mutant strains become undetectable using deep sequencing. J Infect Dis 214:1687-1694

6. Ramirez S, Mikkelsen LS, Gottwein JM, Bukh J (2016) Robust HCV genotype 3 a infectious cell culture system permits identification of escape variants with resistance to sofosbuvir. Gastroenterol. doi:10.1053/j. gastro.2016.07.013

7. Mizokami M, Dvory-Sobol H, Izumi N, Nishiguchi S, Doehle B, Svarovskaia ES, De-Oertel S, Knox S, Brainard DM, Miller MD et al (2016) Resistance analyses of Japanese hepatitis C-infected patients receiving sofosbuvir or ledipasvir/sofosbuvir containing regimens in phase 3 studies. J Viral Hepat 23:780-788

8. Werner CR, Schwarz JM, Egetemeyr DP, Beck R, Malek NP, Lauer UM, Berg CP (2016) Second-generation direct-acting-antiviral hepatitis C virus treatment: efficacy, safety, and predictors of SVR12. World J Gastroenterol 22:8050-8059

9. Alavian SM, Hajarizadeh B, Bagheri LK, Sharafi H, Ebrahimi DN, Merat S, Mohraz M, Mardani M, Fattahi MR, Poustchi H et al (2016) Recommendations for the clinical management of hepatitis $C$ in Iran: a consensusbased national guideline. Hepat Mon 16:e40959

10. Du N-N, Peng Z-G, Bi C-W, Tang S, Li Y-H, Li J-R, Zhu Y-P, Zhang J-P, Wang Y-X, Jiang J-D et al (2013) N-substituted benzyl matrinic acid derivatives inhibit hepatitis $\mathrm{C}$ virus ( $\mathrm{HCV}$ ) replication through down-regulating host heat-stress cognate 70 (Hsc70) expression. PLoS ONE 8:e58675

11. Peng Z-G, Fan B, Du N-N, Wang Y-P, Gao L-M, Li Y-H, Li Y-H, Liu F, You X-F, Han Y-X et al (2010) Small molecular compounds that inhibit hepatitis $C$ virus replication through destabilizing heat shock cognate 70 messenger RNA. Hepatology 52:845-853
12. Tang S, Li Y-H, Cheng X-Y, Li Y-H, Wang H-Q, Kong L-Y, Zhang X, Jiang J-D, Song D-Q (2016) SAR evolution and discovery of benzenesulfonyl matrinanes as a novel class of potential coxsakievirus inhibitors. Future Med Chem 8:495-508

13. Fu HG, Tang S, Li YH, Song DQ, Wang YX (2014) Synthesis and antitubercular activities of novel 12-n-substituted matrinic acid derivatives. Chin J Synth Chem 6:739-743

14. Tang S, Kong L-Y, Li Y-H, Jiang J-D, Gao L-M, Cheng X-Y, Ma L-L, Zhang X, Li Y-H, Song D-Q (2015) Novel N-benzenesulfonyl sophocarpinol derivatives as coxsackie $B$ virus inhibitors. ACS Med Chem Lett 6:183-186

15. Bi C-W, Zhang C-X, Li Y-H, Tang S, Wang S, Shao R-G, Fu H-G, Su F, Song D-Q (2014) Synthesis and biological evaluation of sophoridinol derivatives as a novel family of potential anticancer agents. ACS Med Chem Lett 5:1225-1229

16. Li Y-H, Peng Z-G, Gao L-M, Song D-Q (2014) Synthesis and biological evaluation of sophocarpinic acid derivatives as anti-HCV agents. Acta Pharm Sin B 4:307-312

17. Du N-N, Li X, Wang Y-P, Liu F, Liu Y-X, Li C-X, Peng Z-G, Gao L-M, Jiang J-D, Song D-Q (2011) Synthesis, structure-activity relationship and biological evaluation of novel N-substituted matrinic acid derivatives as host heat-stress cognate 70 (Hsc70) down-regulators. Bioorg Med Chem Lett 21:4732-4735

18. Gao L-M, Tang S, Wang Y-X, Gao R-M, Zhang X, Peng Z-G, Li J-R, Jiang J-D, Li Y-H, Song D-Q (2013) Synthesis and biological evaluation of $\mathrm{N}$-substituted sophocarpinic acid derivatives as coxsackievirus B3 inhibitors. ChemMedChem 8:1545-1553

\section{Submit your manuscript to a SpringerOpen ${ }^{\circ}$ journal and benefit from:}

- Convenient online submission

Rigorous peer review

- Open access: articles freely available online

- High visibility within the field

- Retaining the copyright to your article

Submit your next manuscript at springeropen.com 